\title{
Structural Study and Vibrational Assignments of Anticonvulsant Topiramate by using DFT calculations and Two Harmonic Force Fields
}

\author{
José Ruiz Hidalgo 1(i), Silvia Antonia Brandán 1,*(i) \\ 1 Cátedra de Química General, Instituto de Química Inorgánica, Facultad de Bioquímica, Química y Farmacia, Universidad \\ Nacional de Tucumán, Ayacucho 471, 4000, San Miguel de Tucumán, Tucumán, Argentina \\ * Correspondence: silvia.brandan@fbqf.unt.edu.ar;
}

\begin{abstract}
B3LYP/6-311++G** calculations have been combined with the scaled quantum mechanical force field (SQMFF) methodology to study structural and vibrational properties of anticonvulsant topiramate (TPM) agent. The 123 vibration modes expected for TPM were completely assigned, considering two harmonic force fields. In one case, $\mathrm{C}_{2 \mathrm{~V}}$ symmetries were considered for both $\mathrm{SO}_{2}$ and $\mathrm{NH}_{2}$ groups, while in the other one $\mathrm{C}_{2 \mathrm{~V}}$ and $\mathrm{C}_{3 \mathrm{~V}}$ symmetries for the $\mathrm{NH}_{2}$ and $\mathrm{SO}_{3}$ groups, respectively. The calculated harmonic vibrational frequencies are consistent with the experimental IR and Raman spectra in the solid phase. Very good concordances were found between the theoretical structures in gas phase and aqueous solution and the corresponding experimental reported. Thus, the fused fivemembered ring in TPM produces that the pyranose ring adopts distorted twist-boat conformation, as was experimentally observed. In solution, all calculations were performed with the self-consistent reaction force (SCRF) method by the integral equation formalism variant polarised continuum (IEFPCM) and universal solvation model density (SMD) models. The corrected solvation energy value for TPM in aqueous solution by total non-electrostatic terms and by ZPVE is $-1066.10 \mathrm{~kJ} / \mathrm{mol}$. The bond orders have evidenced that the three $\mathrm{O}$ atoms are not linked of the same form to $\mathrm{S}$ atom. Hence, the $\mathrm{S}$ atom of TPM is practically tetra-coordinate in both media, as evidenced by the high negative MK and NPA charges on the $\mathrm{O}$ atoms linked to it. The AIM study supports the higher stability of TPM in the gas phase while the NBO calculations suggest higher stability in solution. Gap values support the higher reactivity of TPM in solution than in the gas phase. The scaled force constant for both cases are reported for the first time. Comparisons of predicted ${ }^{1} \mathrm{H}$ - and ${ }^{13} \mathrm{C}-\mathrm{NMR}$ spectra with the corresponding experimental ones reveal very good concordances.
\end{abstract}

Keywords: Topiramate; molecular structure; DFT calculations; vibrational spectra.

(C) 2020 by the authors. This article is an open-access article distributed under the terms and conditions of the Creative Commons Attribution (CC BY) license (https://creativecommons.org/licenses/by/4.0/).

\section{Introduction}

Topiramate (TPM) is a sulfamate monosaccharide used to treatment of epilepsy due to its anticonvulsant and antiepileptic properties [1-7]. The experimental structure of TPM was determined by Kubicki et al. [1], while its vibrational characterization by means of the infrared and Raman spectra and thermal properties were reported by Sena et al. [4]. These authors have optimized the structure in the gas phase with the B3LYP/6-31G* method using the Gaussian 98 package, while the tentative vibrational assignments only for some vibration modes were based on published assignments for sulfamates, other correlated materials, and DFT calculations. In that work, some vibration modes corresponding to the $\mathrm{SO}_{3}$ group were no 
descript correctly because they have considered $C_{3 v}$ symmetry for that group but have assigned three symmetric and only one antisymmetric $\mathrm{SO}_{3}$ modes instead of two antisymmetric and one symmetric $\mathrm{SO}_{3}$ modes. Moreover, for the $\mathrm{NH}_{2}$ group, they have reported only the antisymmetric and symmetric stretching modes while the deformation, wagging, rocking, and twisting modes expected for this group have not been reported yet. Hence, to identify TPM in all media by using vibrational spectroscopy, it is necessary to correct and complete assignments of all observed bands in the infrared and Raman spectra to the normal vibration modes. In this work, the TPM structure was optimized in the gas phase and in aqueous solution with the B3LYP/6-311++G** level of theory [8,9] and the Gaussian 09 program [10] while the complete vibrational assignments of TPM were performed combining the normal internal coordinates and the scaled quantum mechanical force fields (SQMFF) methodology with transferable scaling factors and the Molvib program [11-13]. Hence, the complete assignments of 123 vibration modes of TPM in the gas phase were proposed with the B3LYP/6-311++G** level of theory and by using two harmonic force fields. Hence, the normal internal coordinates of the sulfamate group (O-SO $\left.-\mathrm{NH}_{2}\right)$ of TPM have been defined of two forms: in one case, both $\mathrm{SO}_{2}$ and $\mathrm{NH}_{2}$ groups were considered with $C_{2 V}$ symmetries, and, in the other one, the $\mathrm{NH}_{2}$ and $\mathrm{SO}_{3}$ groups present $C_{2 V}$ and $C_{3 V}$ symmetries, respectively. Here, the scaled force constants for those two different force fields obtained for TPM in both media were also reported. Besides, the structural, electronic, and topological properties were also reported in the gas phase and aqueous solution at the same level of theory. The calculations in aqueous solution were carried out with the self-consistent reaction force (SCRF) method and the integral equation formalism variant polarised continuum model (IEFPCM) method and universal solvation model density (SMD) models [14-16]. In addition, reactivities and behaviors of TPM in both media were predicted by using the frontier orbitals and some important descriptors [17-21]. Here, the predicted infrared, Raman, ${ }^{1} \mathrm{H}-,{ }^{13} \mathrm{C}-\mathrm{NMR}$, and ultraviolet-visible spectra were compared with the corresponding available ones [7,22].

\section{Materials and Methods}

The experimental CIF file determined for TPM by using X-ray diffraction was used as an initial theoretical structure and, then, the optimizations of it in the gas phase and aqueous solution were performed with the Gaussian 09 program [10] and the B3LYP/6-311++G** level of theory [8,9]. All calculations in solution were carried out with the self-consistent reaction force (SCRF) method by the integral equation formalism variant polarised continuum (IEFPCM) and universal solvation model density (SMD) models [14-16]. A scheme of the structure of TPM showing all groups present can be seen in Figure 1 together with the definition of three rings. R1 is the six members' ring, while R2 and R3 are the five member's rings. Note that $\mathrm{R} 2$ and $\mathrm{R} 3$ rings have every two $\mathrm{CH}_{3}$ groups. In the vibrational analyses, two harmonic force fields were considered because the normal internal coordinates were built using two forms to define the normal internal coordinates of sulfamate group $\left(\mathrm{O}-\mathrm{SO}_{2}-\mathrm{NH}_{2}\right)$, one form is to consider $C_{2 V}$ symmetries for both $\mathrm{SO}_{2}$ and $\mathrm{NH}_{2}$ groups and, the other one, to consider $C_{2 V}$ and $C_{3 V}$ symmetries for the $\mathrm{NH}_{2}$ and $\mathrm{SO}_{3}$ groups, respectively. Besides, each pair of methyl groups was considered with $C_{2 V}$ symmetry. After that, transferable scaling factors together with each set of normal internal coordinates were used with the scaled quantum mechanical force fields (SQMFF) methodology and the Molvib program to perform the complete vibrational assignments of TPM [11-13]. Here, in the assignments of the bands observed in both infrared 
and Raman spectra to the normal vibration modes, potential energy distribution (PED) contributions $\geq 10 \%$ were considered.

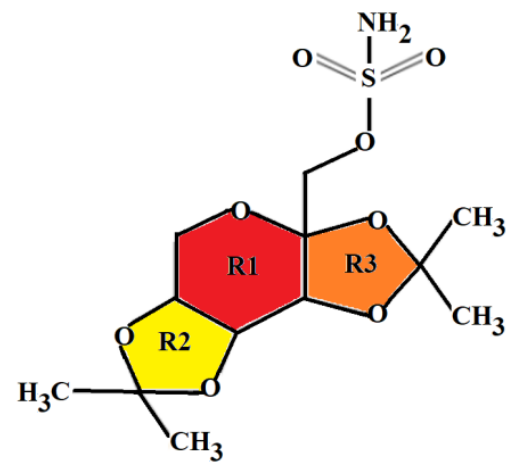

Figure 1. Schematic structure of TPM together with the definition of three rings in different colors.

The Raman spectrum predicted in activities was corrected to intensities by using known equations $[23,24]$. Structural, electronic, topological, and vibrational properties were evaluated in both media and at the same level of theory. Hence, atomic charges, stabilization energies, molecular electrostatic potentials, bond orders, and topological properties were investigated in both media by using the Merz-Kollman (MK) scheme and natural bond orbital (NBO) and atoms in molecules (AIM) calculations [25-28]. The mapped MEP surfaces were obtained with the GaussView program [29], while the volume variation was calculated with the Moldraw program [30]. Energy gap values were calculated from the differences between both frontier orbitals while the chemical potential $(\mu)$, electronegativity $(\chi)$, global hardness $(\eta)$, global softness $(S)$, global electrophilicity index $(\omega)$, and global nucleophilicity index $(E)$ descriptors were calculated with the gap values [17-21]. The ultraviolet-Visible and ${ }^{1} \mathrm{H}$ and ${ }^{13} \mathrm{C}$ NMR spectra were predicted in aqueous solution by using the Time-dependent DFT calculations (TD-DFT) and the gauge-including atomic orbital (GIAO) method at the same level of theory [31].

\section{Results and Discussion}

\subsection{Geometrical parameters and properties in both media.}

The optimized structure of TPM in the gas phase with the atoms labeling is presented in Figure 2 together with the definition of three rings in different colors while in Table 1 can be observed the energy values, dipole moments, and volumes calculated for TPM in both media by using the B3LYP/6-311++G** level of theory. Note that the E corrections by zero-point vibrational energy (ZPVE) are also presented in the table. With (1) are expressed the uncorrected $\mathrm{E}$ values while the corrected ones by ZPVE are identified as (2). In solution, the dipole moment value is higher, as compared with the value in the gas phase because the structure is hydrated with water molecules in this medium, and, for this reason, a slight increase in the volume is also observed, as a consequence of the hydration. The biological properties of TPM can be attributed to donors and acceptors groups of $\mathrm{H}$ bonds; thus, in its structure, there are two donors $\mathrm{N}-\mathrm{H}$ bonds ( $\mathrm{NH}_{2}$ group) and nine acceptors $\mathrm{H}$ bonds ( $\mathrm{N}$ and $\mathrm{O}$ atoms). Khalil et al. reported that the solubility of TPM in water is $9.8 \mathrm{mg} / \mathrm{mL}$; however, it is most soluble in alkaline solutions with a $\mathrm{pH}$ of 9-10 [7]. Hence, the presence of those donors and acceptors groups justify the solubility of TPM in water, and probably a high solvation energy value is expected for TPM in aqueous solution. Taking into account that TPM is very sensitive to water 
and should therefore be well protected from moisture [7], its corrected solvation energy $\left(\Delta \mathrm{G}_{\mathrm{c}}\right)$ is predicted in aqueous solution by using the B3LYP/6-311++g(d,p) method. Figure S1 shows few changes in the orientations and directions of dipole moment vectors predicted for topiramate in both media by using the B3LYP/6-311++G** level of theory.

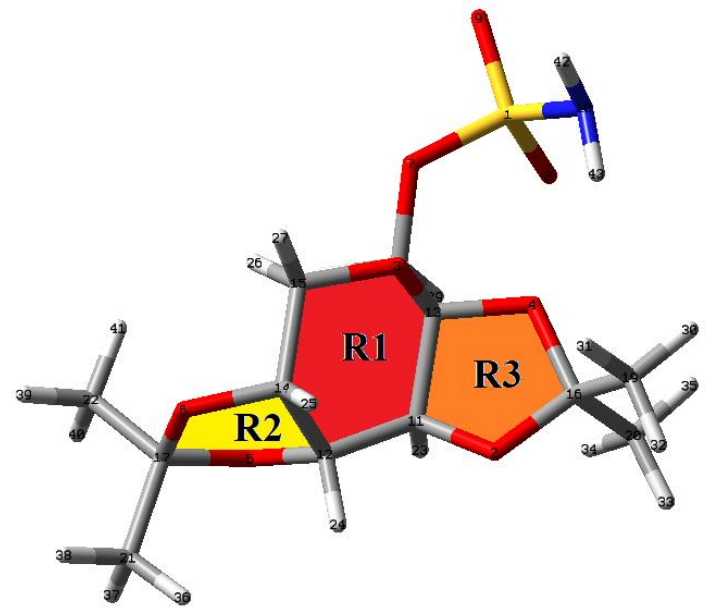

Figure 2. Optimized structure of TPM with the atoms labeling together with the definition of three rings.

Table 1. Calculated total energies $(E)$, dipole moments $(\mu)$, and volumes $(\mathrm{V})$ of TPM in the gas phase and aqueous solution by using the B3LYP/6-311++g(d,p) method.

\begin{tabular}{l|l|l|l|l|l}
\hline \multicolumn{7}{c}{ B3LYP/6-311++g(d,p) method } \\
\hline Medium & $(1)$ E (Hartrees) & $(2)$ EZPVE & $\mu(\mathrm{D})$ & $\mathrm{V}\left(\AA^{3}\right)$ & $\Delta \mathrm{V}$ \\
\hline TPM & -1524.5685 & -1524.2170 & 6.82 & 318.3 & \multirow{2}{*}{1.1} \\
\hline GAS & -1524.9606 & -1524.6139 & 8.62 & 319.4 & \\
\hline PCM/Water &
\end{tabular}

Hence, Table 2 is given the corrected $\Delta \mathrm{G}_{\mathrm{c}}$ values calculated from the difference between the values in solution and in the gas phase. Note that the corrected value by total nonelectrostatic terms and by ZPVE $(-1066.10 \mathrm{~kJ} / \mathrm{mol})$ is slightly higher than the uncorrected by ZPVE (-1053.51 kJ/mol).

Table 2. Corrected and uncorrected solvation energies $\left(\Delta \mathrm{G}_{\mathrm{un}}\right)$ by the total non-electrostatic terms $\left(\Delta \mathrm{G}_{\mathrm{ne}}\right)$ and by zero-point vibrational energy (ZPVE) of TPM in aqueous solution by using the B3LYP/6-311++g(d,p) method.

\begin{tabular}{l|l|l|l}
\hline \multicolumn{4}{c}{ B3LYP/6-311++G(d,p) Method $^{\text {a }}$} \\
\hline Solvation energy $(\mathrm{kJ} / \mathrm{mol})$ & $\Delta \mathrm{G}_{\mathrm{un}}{ }^{*}$ & $\Delta \mathrm{G}_{\mathrm{ne}}$ & $\Delta \mathrm{G}_{\mathrm{c}}$ \\
\hline Medium & -1041.06 & 25.04 & -1066.10 \\
\hline PCM/Water (2) & -1028.47 & 25.04 & -1053.51 \\
\hline PCM/Water (1) &
\end{tabular}

But, both values of TPM are higher than the observed for some salts with antiviral properties such as foscarnet $(-219.64 \mathrm{~kJ} / \mathrm{mol})$ or brincidofovir $(-227.34 \mathrm{~kJ} / \mathrm{mol})[32,33]$ or, for some cationic species of alkaloids as, heroin $(-323.14 \mathrm{~kJ} / \mathrm{mol})$ or scopolamine $(-310.34 \mathrm{~kJ} / \mathrm{mol})$ $[34,35]$. Table 3 shows that the total acceptors and donor groups of TPM cannot justify the high solvation energy because it has a total of 11 groups against foscarnet, which presents 19 groups. Moreover, although those values of compared species were calculated with the B3LYP/6-31G* method, the different methods used cannot explain the great difference in the solvation energy value of TPM. Evidently, the presence of the sulfamate group $\left(\mathrm{O}-\mathrm{SO}_{2}-\mathrm{NH}_{2}\right)$ and, in particular, of $\mathrm{SO}_{3}$ group in TPM, is essential to validate that high solvation energy value in aqueous solution. 
Table 3. Uncorrected solvation energies by ZPVE energies $\left(\Delta \mathrm{G}_{\mathrm{C}}\right)$ and numbers of $\mathrm{N}-\mathrm{H}$ and $\mathrm{O}-\mathrm{H}$ groups and $\mathrm{N}$ and $\mathrm{O}$ atoms present in TPM and in antiviral and alkaloids species in aqueous solution by using the hybrid

B3LYP/6-311++G** and B3LYP/6-31G* methods.

\begin{tabular}{l|l|l|l|l|l|l|l|l|l|l}
\hline $\mathbf{N}^{\mathbf{o}}$ & Species & $\mathbf{\Delta} \mathbf{G}_{\mathbf{C}}$ & $\mathbf{N}-\mathbf{H}$ & $\mathbf{O}-\mathbf{H}$ & $\mathbf{O}$ & $\mathbf{C = O}$ & $\mathbf{N}$ & Total & Groups & Rings \\
\hline 1 & TPM $^{\mathrm{a}}$ & -1053.51 & $2\left(\mathrm{NH}_{2}\right)$ & & 8 & & 1 & 11 & $\mathrm{O}-\mathrm{SO}_{2}$ & $2 \mathrm{R} 5, \mathrm{R} 6$ \\
\hline 2 & Foscarnet $^{\mathrm{b}}$ & -219.64 & & 12 & 5 & 2 & & 19 & $3 \mathrm{Na}_{2} \mathrm{PO}_{3}$ & \\
\hline 3 & Brincidofovir $^{\mathrm{c}}$ & -227.34 & $2\left(\mathrm{NH}_{2}\right)$ & 2 & 7 & 1 & 3 & 15 & $\mathrm{HPO}_{3}$ & $\mathrm{R} 6$ \\
\hline 4 & Heroin $^{\mathrm{d}}$ & -323.14 & 1 & & 5 & 2 & 1 & 9 & & $\mathrm{R} 5,4 \mathrm{R} 6$ \\
\hline 5 & Scopolamine $^{\mathrm{e}}$ & -310.34 & 1 & 1 & 4 & 1 & 4 & 11 & $1 \mathrm{R} 3$ & $2 \mathrm{R} 6, \mathrm{R} 5$ \\
\hline
\end{tabular}

${ }^{\mathrm{a} T h i s ~ w o r k, ~}{ }^{\mathrm{b}}$ From Ref [32], ${ }^{\mathrm{c}}$ From Ref [33], ${ }^{\mathrm{d}}$ From Ref [34], ${ }^{\mathrm{e}}$ From Ref [35]

Comparisons of calculated geometrical parameters of TPM in both media with the corresponding experimental ones determined by Kubicki et al. by X-ray diffraction can be seen in Table 4 as a function of root-mean-square deviation (RMSD) values.

Table 4. Comparisons of calculated geometrical parameters of TPM in the gas phase and aqueous solution by using the B3LYP/6-311++G** method with the corresponding experimental ones by means of the of root-meansquare deviation (RMSD) values.

\begin{tabular}{|c|c|c|c|}
\hline \multirow[t]{2}{*}{ Parameters } & \multicolumn{2}{|c|}{ B3LYP/6-311++G** method $^{\mathrm{a}}$} & \multirow[t]{2}{*}{ Experimental $^{b}$} \\
\hline & Gas & Water & \\
\hline \multicolumn{4}{|c|}{ Bond lengths $(\AA)$} \\
\hline S1-N10 & 1.66 & 1.64 & 1.58 \\
\hline $\mathrm{S} 1-\mathrm{O} 8$ & 1.45 & 1.45 & 1.42 \\
\hline S1-O9 & 1.44 & 1.45 & 1.42 \\
\hline S1-O7 & 1.66 & 1.63 & 1.58 \\
\hline $\mathrm{O} 7-\mathrm{C} 18$ & 1.43 & 1.45 & 1.44 \\
\hline C18-C13 & 1.54 & 1.52 & 1.51 \\
\hline $\mathrm{C} 13-\mathrm{O} 4$ & 1.40 & 1.40 & 1.41 \\
\hline $\mathrm{C} 13-\mathrm{O} 3$ & 1.42 & 1.42 & 1.41 \\
\hline $\mathrm{C} 13-\mathrm{C} 11$ & 1.54 & 1.54 & 1.53 \\
\hline $\mathrm{O} 4-\mathrm{C} 16$ & 1.45 & 1.46 & 1.44 \\
\hline C16-C19 & 1.52 & 1.51 & 1.50 \\
\hline $\mathrm{C} 16-\mathrm{C} 20$ & 1.52 & 1.52 & 1.51 \\
\hline $\mathrm{C} 16-\mathrm{O} 2$ & 1.42 & 1.49 & 1.42 \\
\hline $\mathrm{O} 2-\mathrm{C} 11$ & 1.42 & 1.42 & 1.42 \\
\hline $\mathrm{C} 11-\mathrm{C} 12$ & 1.52 & 1.52 & 1.51 \\
\hline C12-C14 & 1.53 & 1.53 & 1.54 \\
\hline C12-O5 & 1.42 & 1.43 & 1.41 \\
\hline C14-C15 & 1.53 & 1.52 & 1.50 \\
\hline C14-O6 & 1.42 & 1.43 & 1.43 \\
\hline $\mathrm{C} 15-\mathrm{O} 3$ & 1.42 & 1.43 & 1.42 \\
\hline O5-C17 & 1.43 & 1.43 & 1.42 \\
\hline O6-C17 & 1.44 & 1.45 & 1.42 \\
\hline $\mathrm{C} 17-\mathrm{C} 21$ & 1.52 & 1.52 & 1.48 \\
\hline C17-C22 & 1.52 & 1.51 & 1.51 \\
\hline RMSD $^{\mathbf{b}}$ & 0.029 & 0.027 & \\
\hline N10-S1-O7 & 105.8 & 108.4 & 99.9 \\
\hline N10-S1-O8 & 107.4 & 108.1 & 108.9 \\
\hline N10-S1-O9 & 107.8 & 107.6 & 111.6 \\
\hline O8-S1-O9 & 123.6 & 120.5 & 119.0 \\
\hline O8-S1-O7 & 107.8 & 103.4 & 115.6 \\
\hline O9-S1-O7 & 103.1 & 108.4 & 107.3 \\
\hline S1-O7-C18 & 118.6 & 121.2 & 115.6 \\
\hline O7-C18-C13 & 113.5 & 112.0 & 110.4 \\
\hline C18-C13-C11 & 112.9 & 113.0 & 117.1 \\
\hline C18-C13-O3 & 110.3 & 112.3 & 113.6 \\
\hline C18-C13-O4 & 112.8 & 109.6 & 110.3 \\
\hline C13-O4-C16 & 109.4 & 110.6 & 110.3 \\
\hline O3-C13-O4 & 106.3 & 106.0 & 110.7 \\
\hline C13-O3-C15 & 114.2 & 114.7 & 114.1 \\
\hline
\end{tabular}




\begin{tabular}{|c|c|c|c|}
\hline \multirow[t]{2}{*}{ Parameters } & \multicolumn{2}{|c|}{ B3LYP/6-311++G** method $^{\mathrm{a}}$} & \multirow[t]{2}{*}{ Experimental $^{\mathrm{b}}$} \\
\hline & Gas & Water & \\
\hline \multicolumn{4}{|c|}{ Bond lengths $(\AA)$} \\
\hline C13-C11-O2 & 102.4 & 101.8 & 103.3 \\
\hline C13-C11-C12 & 115.8 & 116.7 & 114.3 \\
\hline $\mathrm{O} 4-\mathrm{C} 16-\mathrm{O} 2$ & 105.3 & 104.1 & 104.5 \\
\hline O4-C16-C19 & 110.4 & 109.8 & 108.8 \\
\hline $\mathrm{O} 4-\mathrm{C} 16-\mathrm{C} 20$ & 107.5 & 108.4 & 109.8 \\
\hline C16-O2-C11 & 108.9 & 108.2 & 106.6 \\
\hline C19-C16-C20 & 113.9 & 113.6 & 113.0 \\
\hline C19-C16-O2 & 108.5 & 109.0 & 109.0 \\
\hline $\mathrm{C} 20-\mathrm{C} 16-\mathrm{O} 2$ & 110.9 & 111.5 & 111.4 \\
\hline $\mathrm{O} 2-\mathrm{C} 11-\mathrm{C} 12$ & 108.3 & 108.1 & 107.4 \\
\hline C11-C12-C14 & 116.3 & 116.3 & 114.1 \\
\hline C12-C14-C15 & 111.8 & 112.2 & 112.2 \\
\hline $\mathrm{C} 14-\mathrm{C} 15-\mathrm{O} 3$ & 110.6 & 110.3 & 110.6 \\
\hline $\mathrm{C} 11-\mathrm{C} 12-\mathrm{O} 5$ & 109.4 & 109.6 & 108.5 \\
\hline $\mathrm{C} 12-\mathrm{O} 5-\mathrm{C} 17$ & 106.5 & 107.3 & 107.0 \\
\hline C12-C14-O6 & 103.0 & 102.9 & 104 \\
\hline O6-C14-C15 & 110.5 & 110.2 & 108.8 \\
\hline C14-O6-C17 & 108.9 & 109.4 & 109.0 \\
\hline O6-C17-C21 & 108.4 & 108.6 & 109.3 \\
\hline O6-C17-C22 & 110.4 & 110.3 & 109.2 \\
\hline O5-C17-C21 & 110.9 & 111.0 & 111.0 \\
\hline $\mathrm{O} 5-\mathrm{C} 17-\mathrm{C} 22$ & 108.5 & 108.5 & 109.0 \\
\hline O5-C17-O6 & 105.8 & 105.0 & 103.9 \\
\hline C21-C17-C22 & 112.7 & 113.2 & 114.0 \\
\hline RMSD $^{\mathbf{b}}$ & 2.62 & 3.00 & \\
\hline N10-S1-O7-C18 & -81.45 & -88.31 & -165.7 \\
\hline O8-S1-O7-C18 & 33.24 & 28.79 & -49.1 \\
\hline O9-S1-O7-C18 & 165.44 & 157.67 & 80.5 \\
\hline O7-C18-C13-O3 & 34.35 & 49.10 & -179.3 \\
\hline O7-C18-C13-C11 & 162.0 & 176.98 & -54.7 \\
\hline O7-C18-C13-O4 & -84.29 & -68.42 & 63.3 \\
\hline
\end{tabular}

${ }^{\mathrm{a}}$ This work, ${ }^{\mathrm{b}} \operatorname{Ref}[1]$

Note that the RMSD values are presented only for the bond lengths and angles because the higher deviations are observed in the dihedral angles due to that the calculations predict these parameters with different signs and values than the experimental ones, as can be seen in Table 4. Hence, better correlations are observed for bond lengths and angles (0.029-0.027 and 3.00-2.62 ${ }^{\circ}$ ) despite the calculated values that are, in general, overestimated. In TPM, the fused five-membered ring produces that the pyranose ring adopts distorted twist-boat conformation, as was experimentally observed [1]. A very important result is observed in the calculated $\mathrm{N} 10-\mathrm{O} 3$ distance between the $\mathrm{N}$ atom and the $\mathrm{O} 3$ pyranose ring oxygen atom because the calculated values in the gas phase and aqueous solution are respectively of 3.349 and $3.867 \AA$ while the experimental value is $5.965 \AA$. This N10-O3 distance is probably related to the biological activity of TPM because it connects the hydrophilic part with the corresponding hydrophobic one. These structural results have shown that the B3LYP/6$311++\mathrm{g}(\mathrm{d}, \mathrm{p})$ method generates a very good structure to perform the vibrational study by using the normal internal coordinates analysis.

\subsection{Atomic charges, molecular electrostatic potentials (MEP), and bond orders (BO) studies.}

The above studies have evidenced that the $\left(\mathrm{O}-\mathrm{SO}_{2}-\mathrm{NH}_{2}\right)$ sulfamate group plays an important role in the structural properties of TPM in both media and, probably, in its pharmacological properties and, in particular, it could have an influence on the high solvation energy value in aqueous solution. Hence, the atomic charges on the atoms of that group should 
be first compared with the corresponding to other $\mathrm{O}$ atoms of rings and, then, analyzed among them in order to determine the grade of influence of charges on the properties. This way, atomic Merz-Kollman (MK) [28], Mulliken, and natural population atomic (NPA) charges were calculated on all atoms of TPM in the gas phase, and aqueous solution by using the B3LYP/6$311++\mathrm{G}^{* *}$ method and the results are presented in Table $\mathrm{S} 1$ of supporting material. The variations of those three types of charges only for the $\mathrm{S}, \mathrm{O}$, and $\mathrm{N}$ atoms of TPM in both media can be seen in Figure 3. This figure shows that the three charges on S1 atom in both media present high positive signs while the MK and NPA charges on the $\mathrm{O}$ and $\mathrm{N}$ atoms have negative signs.
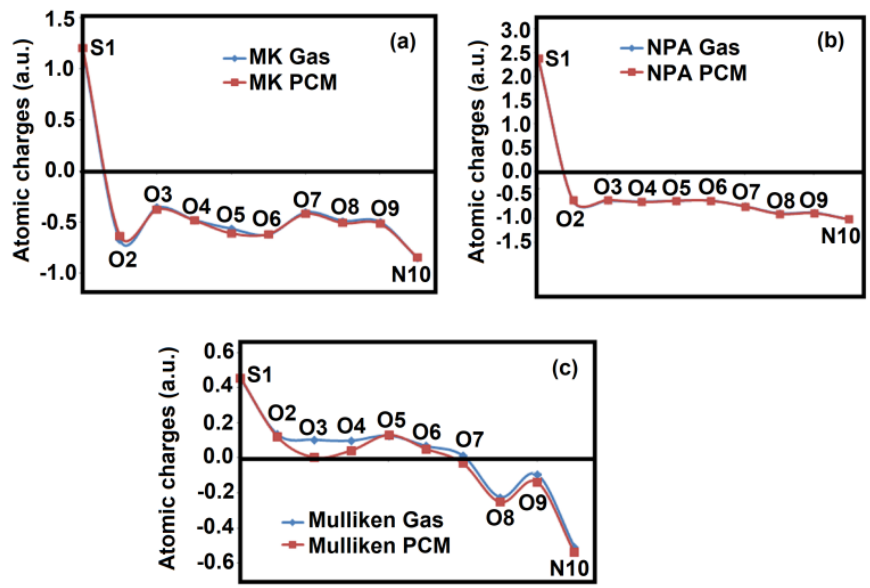

Figure 3. Variations in the atomic Merz-Kollman (MK), Mulliken, and natural population atomic (NPA) charges of TPM in the gas phase and aqueous solution by using the hybrid B3LYP/6-311++G** method.

On the contrary, the Mulliken charges on O8, O9, and N10 present negative signs in both media, while the corresponding to $\mathrm{O} 2, \mathrm{O} 3, \mathrm{O} 4, \mathrm{O} 5$, and $\mathrm{O} 6$ atoms present positive signs. Note that only the different signs of Mulliken charges on N10 and O3 atoms could explain the shortening in the calculated N10-O3 distance in the gas phase and aqueous solution (3.349 and $3.867 \AA$ ), as compared with the experimental value (5.965 $\AA$ ). On the other side, the three O atoms that belong to the sulfamate group $(\mathrm{O} 7, \mathrm{O} 8, \mathrm{O} 9)$ present practically the same $\mathrm{MK}$ and NPA charges while the Mulliken charges on O8 is most negative than the observed on O9 and O7 atoms. Besides, $\mathrm{O} 7$ shows a positive sign in the gas phase and a negative sign in solution. Thus, the Mulliken charges on three $\mathrm{O}$ atoms of the $\mathrm{O}-\mathrm{SO}_{2}-\mathrm{NH}_{2}$ group will explain the differences between the properties in the gas phase and in solution. In relation to the $\mathrm{H}$ atoms, it is observed that the two $\mathrm{H} 42$ and $\mathrm{H} 43$ atoms that belong to the $\mathrm{NH}_{2}$ group present the highest positive values than the other ones.

If now the molecular electrostatic potentials (MEP) values are analyzed on all atoms from Table S1, we observed that the values change a little in solution evidencing the most negative value on the $\mathrm{S}$ atom while the less negative values are observed on the $\mathrm{H}$ atoms, following, in general, the tendency: $\mathrm{S}>\mathrm{O}>\mathrm{N}>\mathrm{C}>\mathrm{H}$. However, when the mapped MEP surface for TPM in the gas phase by using the B3LYP/6-31G* method is graphed and presented in Figure 4 as transparent and solid mapped MEP surfaces, the different colorations clearly reveal which are the main reaction sites. Hence, in the two mapped MEP surfaces of Figure 4a and $4 \mathrm{~b}$ can be seen the strong red colors on the $\mathrm{O}$ atoms of $\mathrm{O}-\mathrm{SO}_{2}$ - of sulfamate group while the intense blue colors on the $\mathrm{H}$ atoms of the $\mathrm{NH}_{2}$ group. 


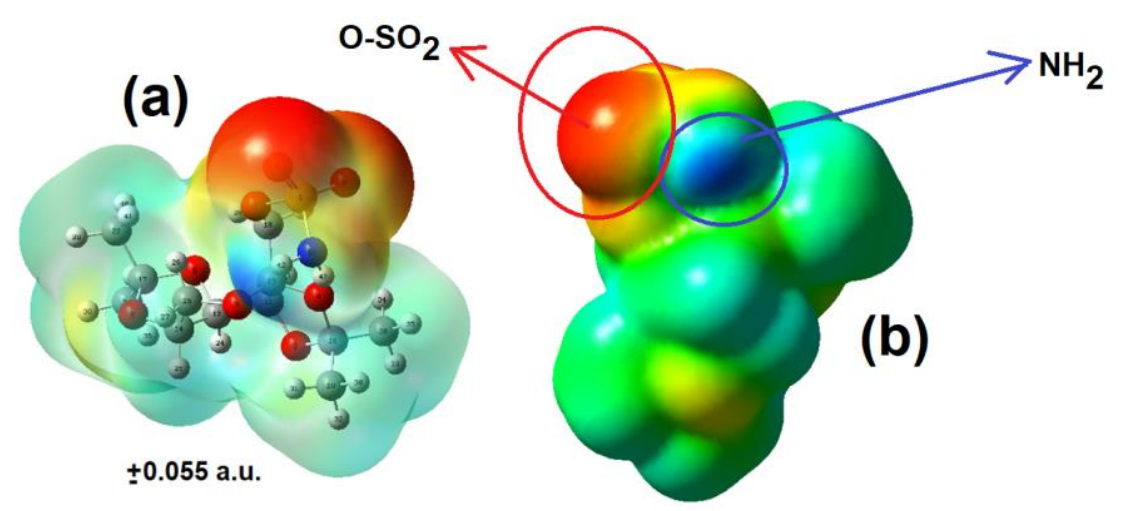

Figure 4. The calculated electrostatic potential surface on the molecular surface of TPM in the gas phase $( \pm$ 0.055 a.u.). B3LYP functional and 6-31G* basis set. Isodensity value of 0.005 .

Note that other regions with orange and light blue colors are also observed on the $\mathrm{O}$ atoms of rings and on the $\mathrm{H}$ atoms of $\mathrm{CH}_{3}$ groups, respectively. Thus, the red and blue colors, respectively, are attributed to acceptors and donors $\mathrm{H}$ bonds regions, which are known as nucleophilic and electrophilic sites, while the green colors are inert sites. These results are in agreement with that experimental determined by X-ray because the $\mathrm{NH}_{2}$ group acts as a donor for two intermolecular hydrogen bonds, which are formed with the sulfamate O8 oxygen atom and with the $\mathrm{O} 6$ atom of two neighboring molecules [1].

The bond orders (BOs), expressed as Wiberg indexes, are also studied for TPM in both media, which are calculated as totals by atom by using the B3LYP/6-311++G** method and these are presented in Table S1 [25]. Analyzing the BOs only for the ten first atoms, it is observed that the $\mathrm{S}$ and $\mathrm{N}$ atoms present the higher values while the lowers values are observed for the $\mathrm{O} 8$ and $\mathrm{O} 9$ atoms of $\mathrm{O}-\mathrm{SO}_{2}$ - of sulfamate group. Later, the low BOs values observed in those two atoms could indicate that those two atoms are more acceptors of $\mathrm{H}$ bonds than those belonging to rings (most negative charges), as expected because these sites are nucleophilic regions with strong red colors on the mapped MEP surfaces. However, when the Wiberg bond index matrix in the NAO basis is considered for the $\mathrm{S} 1$ and $\mathrm{O} 7, \mathrm{O} 8$, and $\mathrm{O} 9$ atoms of $\mathrm{O}_{-} \mathrm{SO}_{2-}$ group, the values are respectively of $0.6847,1.3236$, and 1.3481 , indicating that the three atoms are not linked of the same form to $\mathrm{S}$ atom. The BO of $\mathrm{S} 1$ atom linked to N10 atom is 0.8912 , a value slightly higher than the observed for the $\mathrm{O} 7$ atom. The sum of all those values is 4.2476, a value approximately similar than observed for $\mathrm{S} 1$ atom in Table S1 (4.2805). In TPM, the S atom is practically tetra-coordinate in both media, as evidenced by the high negative $\mathrm{MK}$ and NPA charges on the $\mathrm{O}$ atoms linked to it.

\subsection{Natural bond orbital (NBO) and atoms in molecules (AIM) studies.}

The NBO program allows the determination of bond orders, NPA charges, Natural atomic orbital occupancies, and to perform the Second Order Perturbation Theory Analysis of Fock Matrix in NBO Basis necessary to investigate donor-acceptor energy interactions among other properties [25]. On the other hand, the AIM 2000 program based in the Bader' theory of atoms in molecules (AIM) is useful to predict different types of interactions as for example, intra-molecular or $\mathrm{H}$ bonds interactions by means of the topological properties [26,27]. Hence, those two programs were used to determine the main delocalization energies of TPM in the gas phase and aqueous solution by using the B3LYP/6-311++ $\mathrm{G}^{* *}$ method, which is presented in Table S2. The exhaustive inspections of results show that only three interactions are observed 
in TPM in both media which are: $\sigma \rightarrow \sigma^{*}, n \rightarrow \sigma^{*}$ and $\sigma^{*} \rightarrow \sigma^{*}$ interactions where the total energy of $n \rightarrow \sigma^{*}$ interactions show the higher values. These latter interactions are performed from lone pairs of $\mathrm{O}$ and $\mathrm{N}$ atoms to different antibonding $\sigma O-C, \sigma C-H, \sigma C-C, \sigma S-O$ and $\sigma S-N$ orbitals while the $\sigma^{*} \rightarrow \sigma^{*}$ interactions are performed from antibonding $51-O 7$ orbitals to antibonding $\sigma S 1-N 10$ and $\sigma 07-C 18$ orbitals. The total sum of energies favors slightly to TPM in solution with a value of $1688.81 \mathrm{~kJ} / \mathrm{mol}$, while in the gas phase, the value is $1656.11 \mathrm{~kJ} / \mathrm{mol}$.

Intra-molecular and $\mathrm{H}$ bonds interactions for TPM in both media were predicted with the topological properties by using the AIM 2000 program [26,27]. Thus, the electron density distribution, $\rho(r)$, the Laplacian values, $\nabla^{2} \rho(r)$, the eigenvalues $(\lambda 1, \lambda 2, \lambda 3)$ of the Hessian matrix and the $\lambda 1 / \lambda 3$ ratios were calculated in the bond critical points (BCPs) and in the ring critical points (RCPs). These properties in the gas phase and aqueous solution are presented in Tables S3 and S4, respectively. The values of $\lambda 1 / \lambda 3<1$ and $\nabla^{2} \rho(r)>0$ indicate that three $\mathrm{H}$ bonds interactions are observed in the gas phase, while in solution, only two $\mathrm{H}$ bonds

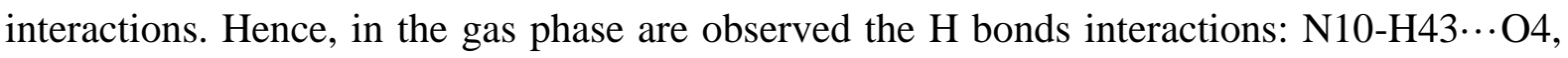
$\mathrm{C} 18-\mathrm{H} 28 \cdots \mathrm{O} 5$, and $\mathrm{C} 15-\mathrm{H} 26 \cdots \mathrm{H} 41$ while in solution only are observed two of them: N10$\mathrm{H} 43 \cdots \mathrm{O} 4$ and $\mathrm{C} 15-\mathrm{H} 26 \cdots \mathrm{H} 41$. Note that the formation of an $\mathrm{H}$ bond implies the formation of a new RCP named RCPN; hence, three new RCPN are formed in the gas phase (RCPN1, RCPN2, and RCPN3) and only two new RCPN in solution. Obviously, the three rings give three RCP1, RCP2, and RCP3. Figure S2 can be seen in the three $\mathrm{H}$ bonds interactions of TPM in the gas phase and the new three RCPN and RCPs. This AIM study supports the higher stability of TPM in the gas phase while the NBO study suggests higher stability in solution.

\subsection{Frontier orbitals studies and global quantum descriptors.}

Biological studies have suggested that TPM has multiple probable sites of action, including sodium channels, GABA receptors, and glutamate (AMPA) [36], which will explain why TPM is efficient in numerous intractable syndromic epilepsies. These different sites of action are also evidenced by the different colorations on its mapped MEP surface. Then, the studies of frontier orbitals and knowledge of gap energies in different media are parameters very important to predict the reactivities and behaviors of TPM in the gas phase and aqueous solution. Hence, the HOMO and LUMO, energy band gaps and the chemical potential $(\mu)$, electronegativity $(\chi)$, global hardness $(\eta)$, global softness $(S)$, global electrophilicity $(\omega)$, and nucleophilicity indexes $(E)$ descriptors were calculated for TPM in both media by using the hybrid B3LYP/6-311++G** method. These parameters in both media are compared in Table S5 with the corresponding to the free bases of scopolamine and promethazine by using the B3LYP/6-31G* method [35,37]. The equations used to compute the descriptors can also be seen in the same table. First, it is observed that TPM is slightly most reactive in solution because its gap value in this medium is a few lower than the value in the gas phase. However, when the gap values for the three species are compared, we observed that the species of antihistaminic promethazine agents present in both media the lower gap values, later the free base of scopolamine and, finally, the higher gap values are observed for topiramate. Taking into account that the lower gap value is related to the most reactive species, the reactivity order is promethazine $(4.7157 / 4.7702 \mathrm{eV})>$ scopolamine $(5.4004 / 5.4758 \mathrm{eV})>$ topiramate $(6.9434 / 6.9316 \mathrm{eV})$. If now the global electrophilicity $(\omega)$ and nucleophilicity indexes $(E)$ are compared, the tendency in both indexes change to: topiramate $(\omega: 2.3503 / 2.3507, E:-14.025 /-$ $13.990 \mathrm{eV})>$ scopolamine $(\omega: 1.7393 / 1.7504, E:-8.2756 /-8.4763 \mathrm{eV})>$ promethazine $(\omega:$ 
1.4911/1.4954, E: -6.2524/-6.3701 eV). These high values of both $\omega$ and $E$ indexes for topiramate could probably explain why the combination of pharmacological properties is unique among currently available antiepileptic drugs and may explain why TPM is effective in both partial and generalized seizures [36].

\subsection{NMR spectra in both media.}

Here, the theoretical ${ }^{1} \mathrm{H}$ - and ${ }^{13} \mathrm{C}-\mathrm{NMR}$ spectra were predicted for topiramate in aqueous solution by using the B3LYP/6-311++G** level of theory and the GIAO method [31]. Then, the predicted ${ }^{1} \mathrm{H}$ - and ${ }^{13} \mathrm{C}-\mathrm{NMR}$ chemical shifts were compared with the experimental available for topiramate in DMSO- $d 6$ taken from Ref [7] by using the root-mean-square deviation (RMSD) values. In Tables S6 and S7 have presented the comparisons of predicted ${ }^{1} \mathrm{H}$ - and ${ }^{13} \mathrm{C}-\mathrm{NMR}$ chemical shifts by using RMSD values. Very good correlations with low RMSD values were obtained for the TPM gas phase and aqueous solution with values between 0.42 and $0.38 \mathrm{ppm}$ for the $\mathrm{H}$ atoms, while for the $\mathrm{C}$ atoms, the RMSD values increase to 4.69 and $5.01 \mathrm{ppm}$. These low RMSD values for topiramate suggest that the two structures in both media can be used to perform the vibrational studies and the determinations of corresponding harmonic force fields.

\subsection{Vibrational study.}

In the published tentative vibrational assignments of topiramate by Sena et al. [4], with the B3LYP/6-31G* method using the Gaussian 98 package, some vibration modes corresponding to the $\mathrm{SO}_{3}$ group considered with $C_{3 v}$ symmetry have not been descript correctly because they have assigned three symmetric and only one antisymmetric $\mathrm{SO}_{3}$ modes instead of two antisymmetric and one symmetric $\mathrm{SO}_{3}$ modes. Moreover, they have reported only the antisymmetric and symmetric stretching modes for the $\mathrm{NH}_{2}$ group while the deformation, wagging, rocking, and twisting modes expected for this group were not assigned. In this study, we have performed the complete assignments of 123 vibration modes of TPM in the gas phase with the B3LYP/6-311++G** level of theory and taking into account two harmonic force fields. Hence, the normal internal coordinates of the sulfamate group $\left(\mathrm{O}-\mathrm{SO}_{2}-\mathrm{NH}_{2}\right)$ of TPM have been defined of two forms: in one case, both $\mathrm{SO}_{2}$ and $\mathrm{NH}_{2}$ groups were considered with $C_{2 V}$ symmetries, and, in the other one, the $\mathrm{NH}_{2}$ and $\mathrm{SO}_{3}$ groups present $C_{2 V}$ and $C_{3 V}$ symmetries, respectively. On the other hand, each pair of methyl groups was considered with $C_{2 V}$ symmetry. The B3LYP/6-311++G** level of theory has optimized the TPM structures in both media with $C_{1}$ symmetries and its expected 123 vibration modes present activity in the infrared and Raman spectra. The predicted infrared and Raman spectra of TPM in both media are compared in Figures 5 and 6 with the corresponding available taken from Ref [22] for TPM in the solidstate. Reasonable correlations were found between the predicted spectra with the corresponding available ones, as can be seen in Figs 5 and 6. The predicted Raman spectrum in activities was corrected to intensities with known equations [23,24]. Note that the intensities of some bands change in the predicted spectra in solution and, in particular, in the Raman spectrum, as shown in Figure 6.

In the determination of the two harmonic force fields of TPM were used the two definitions of normal internal coordinates of sulfamate group $\left(\mathrm{O}-\mathrm{SO}_{2}-\mathrm{NH}_{2}\right)$ and the scaled quantum mechanical force field (SQMFF) methodology with the Molvib program [11-13]. 
Transferable scaling factors and potential energy distribution (PED) contributions $\geq 10 \%$ were employed to perform the vibrational assignments.

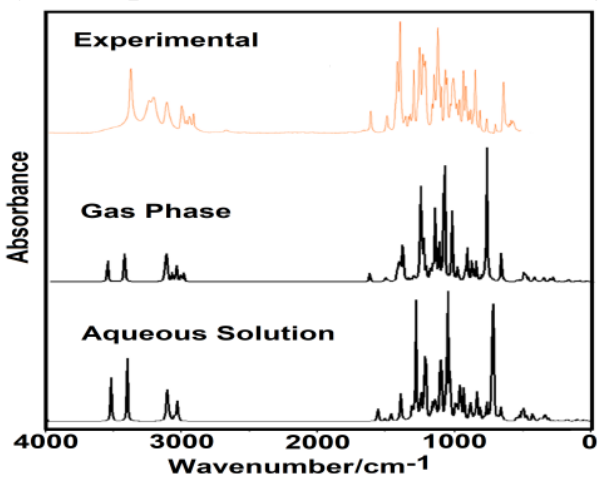

Figure 5. Experimental available Infrared spectra of TPM in solid phase [22] compared with the predicted in the gas phase and solution by using the hybrid B3LYP/6-311++G** method.

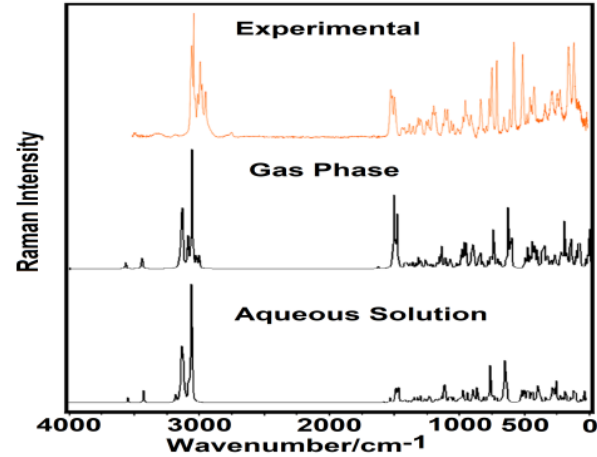

Figure 6. Experimental available Raman spectra of TPM in solid phase [22] compared with the predicted in the gas phase and solution by using the hybrid B3LYP/6-311++G** method.

Observed and calculated wavenumbers for TPM in the gas phase by using B3LYP/6$311++\mathrm{G}^{* *}$ calculations and the corresponding assignments for the two proposed harmonic force fields can be seen in Table 5. The two calculated harmonic force fields for TPM can be obtained upon request. Then, some important assignments taking into account the two proposed force fields are discussed below.

Table 5. Observed and calculated wavenumbers $\left(\mathrm{cm}^{-1}\right)$ together with two assignments proposed for Topimarate in the gas phase by using the B3LYP/6-311++G** method.

\begin{tabular}{|c|c|c|c|c|c|c|c|c|}
\hline \multirow{2}{*}{\multicolumn{3}{|c|}{ Experimental }} & \multicolumn{6}{|c|}{ B3LYP/6-311++G** method $^{a}$} \\
\hline & & & \multirow[t]{2}{*}{ Calc. ${ }^{\text {b }}$} & \multirow[t]{2}{*}{ Int. $^{c}$} & \multicolumn{2}{|c|}{$\mathrm{NH}_{2}\left(C_{2 V}\right), \mathrm{SO}_{2}\left(C_{2 V}\right)$} & \multicolumn{2}{|c|}{$\mathrm{NH}_{2}\left(C_{2 V}\right), \mathrm{SO}_{3}\left(C_{3} V\right)$} \\
\hline ATR & IR & Raman & & & SQM $^{\mathrm{d}}$ & Assignments $^{\mathrm{a}}$ & SQM $^{\mathrm{d}}$ & Assignments $^{\mathrm{a}}$ \\
\hline $3396 \mathrm{sh}$ & $3444 \mathrm{sh}$ & $3395 w$ & 3578 & 74.7 & 3430 & $\mathrm{~V}_{\mathrm{a}} \mathrm{NH}_{2}$ & 3430 & $\mathrm{~V}_{\mathrm{a}} \mathrm{NH}_{2}$ \\
\hline $3381 w$ & $3376 s$ & & 3452 & 132.5 & 3310 & $\mathrm{v}_{\mathrm{s}} \mathrm{NH}_{2}$ & 3310 & $\mathrm{v}_{\mathrm{s}} \mathrm{NH}_{2}$ \\
\hline $3241 \mathrm{sh}$ & $3237 \mathrm{~m}$ & $3236 w$ & 3165 & 12.9 & 3034 & $v_{\mathrm{a}} \mathrm{CH}_{3}(\mathrm{C} 19)$ & 3034 & $\mathrm{v}_{\mathrm{a}} \mathrm{CH}_{3}(\mathrm{C} 19)$ \\
\hline $3212 w$ & $3208 \mathrm{~m}$ & & 3156 & 2.0 & 3025 & $v_{\mathrm{a}} \mathrm{CH}_{2}(\mathrm{C} 18)$ & 3025 & $\mathrm{v}_{\mathrm{a}} \mathrm{CH}_{2}(\mathrm{C} 18)$ \\
\hline \multirow[t]{7}{*}{$3112 \mathrm{w}$} & $3111 \mathrm{~m}$ & $3120 w$ & 3152 & 27.1 & 3022 & $v_{\mathrm{a}} \mathrm{CH}_{3}(\mathrm{C} 22)$ & 3022 & $v_{\mathrm{a}} \mathrm{CH}_{3}(\mathrm{C} 22)$ \\
\hline & & & 3148 & 23.4 & 3018 & $v_{\mathrm{a}} \mathrm{CH}_{3}(\mathrm{C} 20)$ & 3018 & $v_{\mathrm{a}} \mathrm{CH}_{3}(\mathrm{C} 20)$ \\
\hline & & & 3148 & 23.7 & 3017 & $\mathrm{v}_{\mathrm{a}} \mathrm{CH}_{3}(\mathrm{C} 22)$ & 3017 & $\mathrm{v}_{\mathrm{a}} \mathrm{CH}_{3}(\mathrm{C} 22)$ \\
\hline & & & 3146 & 19.3 & 3016 & $v_{\mathrm{a}} \mathrm{CH}_{3}(\mathrm{C} 20)$ & 3016 & $\mathrm{v}_{\mathrm{a}} \mathrm{CH}_{3}(\mathrm{C} 20)$ \\
\hline & & & 3143 & 22.4 & 3013 & $v_{\mathrm{a}} \mathrm{CH}_{3}(\mathrm{C} 21)$ & 3013 & $v_{\mathrm{a}} \mathrm{CH}_{3}(\mathrm{C} 21)$ \\
\hline & & & 3139 & 7.8 & 3009 & $v_{\mathrm{a}} \mathrm{CH}_{2}(\mathrm{C} 15)$ & 3009 & $\mathrm{v}_{\mathrm{a}} \mathrm{CH}_{2}(\mathrm{C} 15)$ \\
\hline & & & 3139 & 20.5 & 3009 & $\mathrm{~V}_{\mathrm{a}} \mathrm{CH}_{3}(\mathrm{C} 21)$ & 3009 & $\mathrm{v}_{\mathrm{a}} \mathrm{CH}_{3}(\mathrm{C} 21)$ \\
\hline $3008 \mathrm{sh}$ & & $3009 \mathrm{vs}$ & 3138 & 3.0 & 3008 & $\mathrm{v}_{\mathrm{a}} \mathrm{CH}_{3}(\mathrm{C} 19)$ & 3008 & $\mathrm{v}_{\mathrm{a}} \mathrm{CH}_{3}(\mathrm{C} 19)$ \\
\hline $2999 w$ & $2997 \mathrm{~m}$ & 2996vs & 3102 & 11.9 & 2974 & $v_{\mathrm{s}} \mathrm{CH}_{2}(\mathrm{C} 18)$ & 2974 & $\mathrm{v}_{\mathrm{s}} \mathrm{CH}_{2}(\mathrm{C} 18)$ \\
\hline $2987 \mathrm{sh}$ & & $2968 \mathrm{~m}$ & 3101 & 22.9 & 2973 & vC14-H25 & 2973 & vC14-H25 \\
\hline $2960 w$ & $2957 w$ & $2952 \mathrm{~s}$ & 3073 & 16.6 & 2946 & $v_{\mathrm{s}} \mathrm{CH}_{3}(\mathrm{C} 22)$ & 2946 & $v_{\mathrm{s}} \mathrm{CH}_{3}(\mathrm{C} 22)$ \\
\hline \multirow[t]{2}{*}{$2960 w$} & $2957 w$ & $2952 \mathrm{~s}$ & 3072 & 12.6 & 2945 & $v_{\mathrm{s}} \mathrm{CH}_{3}(\mathrm{C} 19)$ & 2945 & $v_{\mathrm{s}} \mathrm{CH}_{3}(\mathrm{C} 19)$ \\
\hline & & & 3071 & 10.5 & 2944 & $v_{\mathrm{s}} \mathrm{CH}_{2}(\mathrm{C} 15)$ & 2944 & $\mathrm{v}_{\mathrm{s}} \mathrm{CH}_{2}(\mathrm{C} 15)$ \\
\hline \multirow[t]{2}{*}{$2940 w$} & $2936 w$ & $2938 s$ & 3067 & 7.2 & 2940 & $v_{\mathrm{s}} \mathrm{CH}_{3}(\mathrm{C} 20)$ & 2940 & $v_{\mathrm{s}} \mathrm{CH}_{3}(\mathrm{C} 20)$ \\
\hline & & & 3065 & 12.2 & 2939 & $v_{\mathrm{s}} \mathrm{CH}_{3}(\mathrm{C} 21)$ & 2939 & $v_{\mathrm{s}} \mathrm{CH}_{3}(\mathrm{C} 21)$ \\
\hline \multirow[t]{2}{*}{$2911 w$} & $2903 m$ & $2916 \mathrm{~m}$ & 3037 & 26.2 & 2911 & vC12-H24 & 2911 & vC12-H24 \\
\hline & & & 3016 & 25.1 & 2892 & $v \mathrm{C} 11-\mathrm{H} 23$ & 2892 & $v \mathrm{C} 11-\mathrm{H} 23$ \\
\hline \multirow[t]{5}{*}{$1571 w$} & $1574 \mathrm{~m}$ & & 1646 & 29.3 & 1573 & $\delta \mathrm{NH}_{2}$ & 1573 & $\delta \mathrm{NH}_{2}$ \\
\hline & $1467 \mathrm{sh}$ & $1461 \mathrm{~s}$ & 1538 & 5.1 & 1470 & $\delta \mathrm{CH}_{2}(\mathrm{C} 15)$ & 1470 & $\delta \mathrm{CH}_{2}(\mathrm{C} 15)$ \\
\hline & & & 1528 & 4.9 & 1460 & $\mathrm{\delta}_{\mathrm{a}} \mathrm{CH}_{3}(\mathrm{C} 19)$ & 1460 & $\mathrm{\delta}_{\mathrm{a}} \mathrm{CH}_{3}(\mathrm{C} 19)$ \\
\hline & 1460sh & & 1527 & 5.6 & 1459 & $\delta_{\mathrm{a}} \mathrm{CH}_{3}(\mathrm{C} 22)$ & 1459 & $\delta_{\mathrm{a}} \mathrm{CH}_{3}(\mathrm{C} 22)$ \\
\hline & 1460sh & & 1526 & 0.8 & 1459 & $\mathrm{\delta}_{\mathrm{a}} \mathrm{CH}_{3}(\mathrm{C} 22)$ & 1459 & $\delta_{\mathrm{a}} \mathrm{CH}_{3}(\mathrm{C} 22)$ \\
\hline
\end{tabular}




\begin{tabular}{|c|c|c|c|c|c|c|c|c|}
\hline \multirow{2}{*}{\multicolumn{3}{|c|}{ Experimental }} & \multicolumn{6}{|c|}{ B3LYP/6-311++G** method $^{\mathrm{a}}$} \\
\hline & & & \multirow[t]{2}{*}{ Calc. $^{\mathrm{b}}$} & \multirow[t]{2}{*}{ Int. $^{c}$} & \multicolumn{2}{|c|}{$\mathrm{NH}_{2}\left(C_{2} V\right), \mathrm{SO}_{2}\left(C_{2 V}\right)$} & \multicolumn{2}{|c|}{$\mathrm{NH}_{2}\left(C_{2} \mathrm{~V}\right), \mathrm{SO}_{3}\left(C_{3} \mathrm{~V}\right)$} \\
\hline \multirow[t]{2}{*}{ ATR } & IR & Raman & & & $\mathrm{SQM}^{\mathrm{d}}$ & Assignments $^{\mathrm{a}}$ & SQM $^{\mathrm{d}}$ & Assignments $^{\mathrm{a}}$ \\
\hline & & & 1525 & 0.8 & 1458 & $\delta_{\mathrm{a}} \mathrm{CH}_{3}(\mathrm{C} 20)$ & 1458 & $\delta_{\mathrm{a}} \mathrm{CH}_{3}(\mathrm{C} 20)$ \\
\hline \multirow[t]{6}{*}{$1446 \mathrm{w}$} & $1452 \mathrm{~m}$ & $1451 \mathrm{~s}$ & 1509 & 0.7 & 1442 & $\delta_{\mathrm{a}} \mathrm{CH}_{3}(\mathrm{C} 21)$ & 1442 & $\delta_{\mathrm{a}} \mathrm{CH}_{3}(\mathrm{C} 21)$ \\
\hline & $1445 \mathrm{sh}$ & & 1509 & 1.3 & 1442 & $\delta_{\mathrm{a}} \mathrm{CH}_{3}(\mathrm{C} 19)$ & 1442 & $\delta_{\mathrm{a}} \mathrm{CH}_{3}(\mathrm{C} 19)$ \\
\hline & & & 1508 & 4.3 & 1441 & $\delta \mathrm{CH}_{2}(\mathrm{C} 18)$ & 1441 & $\delta \mathrm{CH}_{2}(\mathrm{C} 18)$ \\
\hline & $1438 \mathrm{sh}$ & $1436 \mathrm{~s}$ & 1504 & 0.1 & 1437 & $\delta_{\mathrm{a}} \mathrm{CH}_{3}(\mathrm{C} 21)$ & 1437 & $\delta_{\mathrm{a}} \mathrm{CH}_{3}(\mathrm{C} 21)$ \\
\hline & $1438 \mathrm{sh}$ & & 1503 & 0.0 & 1437 & $\delta_{\mathrm{a}} \mathrm{CH}_{3}(\mathrm{C} 20)$ & 1437 & $\delta_{\mathrm{a}} \mathrm{CH}_{3}(\mathrm{C} 20)$ \\
\hline & & & 1445 & 24.2 & 1399 & $\rho \mathrm{C} 12-\mathrm{H} 24$ & 1399 & $\rho \mathrm{C} 12-\mathrm{H} 24$ \\
\hline \multirow[t]{2}{*}{$1383 \mathrm{sh}$} & $1384 \mathrm{sh}$ & $1386 \mathrm{w}$ & 1444 & 17.6 & 1381 & $\delta_{\mathrm{s}} \mathrm{CH}_{3}(\mathrm{C} 20)$ & 1381 & $\delta_{\mathrm{s}} \mathrm{CH}_{3}(\mathrm{C} 20)$ \\
\hline & & & 1440 & 4.9 & 1380 & $\delta_{\mathrm{s}} \mathrm{CH}_{3}(\mathrm{C} 22)$ & 1380 & $\delta_{\mathrm{s}} \mathrm{CH}_{3}(\mathrm{C} 22)$ \\
\hline \multirow[t]{2}{*}{$1370 \mathrm{~m}$} & $1374 \mathrm{~s}$ & $1370 w$ & 1432 & 23.8 & 1376 & $\rho^{\prime} \mathrm{C} 14-\mathrm{H} 25, \delta_{\mathrm{s}} \mathrm{CH}_{3}(\mathrm{C} 20)$ & 1376 & $\rho^{\prime} \mathrm{C} 14-\mathrm{H} 25, \delta_{\mathrm{s}} \mathrm{CH}_{3}(\mathrm{C} 20)$ \\
\hline & & & 1430 & 21.9 & 1372 & $\delta_{\mathrm{s}} \mathrm{CH}_{3}(\mathrm{C} 21)$ & 1372 & $\delta_{\mathrm{s}} \mathrm{CH}_{3}(\mathrm{C} 21)$ \\
\hline \multirow[t]{3}{*}{$1367 \mathrm{sh}$} & & & 1422 & 35.7 & 1367 & $\delta_{\mathrm{s}} \mathrm{CH}_{3}(\mathrm{C} 19)$ & 1367 & $\delta_{\mathrm{s}} \mathrm{CH}_{3}(\mathrm{C} 19)$ \\
\hline & & & 1412 & 19.0 & 1364 & $\mathrm{wagCH}_{2}(\mathrm{C} 18)$ & 1364 & $\mathrm{wagCH}_{2}(\mathrm{C} 18)$ \\
\hline & & & 1403 & 174.9 & 1362 & $\rho \mathrm{C} 11-\mathrm{H} 23$ & 1362 & $\rho \mathrm{C} 11-\mathrm{H} 23$ \\
\hline \multirow[t]{3}{*}{$1348 \mathrm{~s}$} & $1356 \mathrm{vs}$ & $1354 w$ & 1402 & 0.5 & 1352 & $\mathrm{vaSO}_{2}$ & 1351 & $v_{\mathrm{a}} \mathrm{SO}_{3}$ \\
\hline & & $1338 w$ & 1384 & 3.9 & 1334 & $\rho_{\mathrm{CH}}(\mathrm{C} 15) \rho \mathrm{C} 14-\mathrm{H} 25$ & 1334 & $\rho \mathrm{CH}_{2}(\mathrm{C} 15)$ \\
\hline & & & 1359 & 9.6 & 1326 & $\rho^{\prime} \mathrm{C} 11-\mathrm{H} 23$ & 1326 & $\rho^{\prime} \mathrm{C} 11-\mathrm{H} 23$ \\
\hline $1317 w$ & $1313 w$ & $1310 \mathrm{w}$ & 1343 & 5.6 & 1310 & $\rho^{\prime} \mathrm{C} 12-\mathrm{H} 24$ & 1310 & $\rho^{\prime} \mathrm{C} 12-\mathrm{H} 24$ \\
\hline $1309 w$ & $1288 w$ & $1288 w$ & 1325 & 18.7 & 1298 & $\rho_{\mathrm{CH}}(\mathrm{C} 18), v \mathrm{C} 11-\mathrm{C} 12$ & 1298 & $\rho \mathrm{CH}_{2}(\mathrm{C} 18), v \mathrm{C} 11-\mathrm{C} 12$ \\
\hline $1284 w$ & $1288 w$ & $1278 \mathrm{~m}$ & 1317 & 10.9 & 1281 & $\rho^{\prime} \mathrm{C} 14-\mathrm{H} 25$ & 1281 & $\rho^{\prime} \mathrm{C} 14-\mathrm{H} 25, \rho \mathrm{C} 14-\mathrm{H} 25$ \\
\hline $1276 w$ & $1277 \mathrm{w}$ & $1266 \mathrm{~m}$ & 1290 & 17.0 & 1255 & $\mathrm{wagCH}_{2}(\mathrm{C} 15)$ & 1255 & wagCH$_{2}(\mathrm{C} 15)$ \\
\hline \multirow[t]{2}{*}{$1245 \mathrm{~s}$} & $1248 \mathrm{~s}$ & 1250sh & 1280 & 9.8 & 1240 & $\nu \mathrm{C} 17-\mathrm{C} 22, \rho \mathrm{CH}_{3}(\mathrm{C} 21)$ & 1240 & $v \mathrm{C} 17-\mathrm{C} 22, \rho \mathrm{CH}_{3}(\mathrm{C} 21)$ \\
\hline & & $1234 \mathrm{sh}$ & 1270 & 270.8 & 1230 & $\beta \mathrm{R}_{1}(\mathrm{~A} 2), \rho \mathrm{CH}_{3}(\mathrm{C} 20)$ & 1230 & $\beta \mathrm{R}_{1}(\mathrm{~A} 2), \rho \mathrm{CH}_{3}(\mathrm{C} 20)$ \\
\hline $1219 \mathrm{sh}$ & $1223 \mathrm{sh}$ & $1223 \mathrm{~m}$ & 1265 & 46.8 & 1223 & vC16-C20,vC16-C19 & 1223 & vC16-C20,vC16-C19 \\
\hline $1201 \mathrm{~s}$ & $1209 \mathrm{~s}$ & $1208 \mathrm{~m}$ & 1250 & 141.0 & 1208 & $\mathrm{vC} 17-\mathrm{C} 21$ & 1208 & $v \mathrm{C} 17-\mathrm{C} 21$ \\
\hline $1177 \mathrm{~s}$ & $1184 \mathrm{~s}$ & $1182 \mathrm{~m}$ & 1231 & 32.5 & 1186 & wagCC 2 (C16) & 1186 & $v \mathrm{C} 13-\mathrm{O} 4$ \\
\hline $1168 \mathrm{~s}$ & $1177 \mathrm{~s}$ & $1173 \mathrm{~s}$ & 1204 & 20.5 & 1165 & $\rho \mathrm{NH}_{2}$ & 1165 & $\rho \mathrm{NH}_{2}$ \\
\hline $1168 \mathrm{~s}$ & $1163 \mathrm{~s}$ & & 1197 & 30.4 & 1162 & wagCC $2(\mathrm{C} 17) \rho \mathrm{CH}_{3}(\mathrm{C} 22)$ & 1162 & wagCC $2(\mathrm{C} 17) \rho \mathrm{CH}_{3}(\mathrm{C} 22)$ \\
\hline $1159 \mathrm{~s}$ & & $1159 \mathrm{~m}$ & 1184 & 32.4 & 1156 & vC13-C18 & 1156 & $\mathrm{vC13-C18}$ \\
\hline $1159 \mathrm{~s}$ & & $1159 \mathrm{~m}$ & 1167 & 159.5 & 1126 & $v_{s} \mathrm{SO}_{2 v} \mathrm{C} 13-\mathrm{C} 11$ & 1126 & $v \mathrm{C} 13-\mathrm{C} 11$ \\
\hline $1159 \mathrm{~s}$ & & & 1162 & 109.5 & 1119 & $v_{\mathrm{s}} \mathrm{SO}_{2}$ & 1119 & $v_{\mathrm{s}} \mathrm{SO}_{3} v_{\mathrm{a}} \mathrm{SO}_{3}$ \\
\hline 1107 & $1112 \mathrm{sh}$ & $1111 \mathrm{~m}$ & 1138 & 14.2 & 1101 & vC14-C15,vC13-C11 & 1101 & $v \mathrm{C} 14-\mathrm{C} 15$ \\
\hline $1094 \mathrm{~s}$ & $1101 \mathrm{~s}$ & $1097 \mathrm{~s}$ & 1137 & 92.1 & 1088 & $\mathrm{vC} 11-\mathrm{O} 2$ & 1088 & $\mathrm{vC} 11-\mathrm{O} 2$ \\
\hline \multirow[t]{2}{*}{$1063 \mathrm{vs}$} & $1069 \mathrm{vs}$ & $1081 \mathrm{~s}$ & 1115 & 8.9 & 1065 & $\mathrm{vC} 12-\mathrm{O} 5$ & 1065 & vC14-O6 \\
\hline & 1062sh & $1057 \mathrm{~m}$ & 1104 & 125.3 & 1059 & vC15-O3,vC14-O6 & 1059 & $v \mathrm{C} 15-\mathrm{O} 3, v \mathrm{C} 14-\mathrm{O} 6$ \\
\hline $1054 \mathrm{~s}$ & & & 1097 & 311.6 & 1055 & vC15-O3 & 1055 & $v \mathrm{C} 15-\mathrm{O} 3$ \\
\hline \multirow[t]{2}{*}{$1039 \mathrm{~s}$} & $1044 \mathrm{~s}$ & $1041 w$ & 1093 & 29.3 & 1043 & vC14-O6 & 1043 & vC14-O6,vC15-O3 \\
\hline & $1016 \mathrm{~s}$ & $1016 \mathrm{w}$ & 1058 & 6.4 & 1013 & vC15-O3,vC14-C15 & 1013 & $v \mathrm{C} 15-\mathrm{O} 3, v \mathrm{C} 14-\mathrm{C} 15$ \\
\hline $1006 \mathrm{~s}$ & $1005 \mathrm{~s}$ & $1007 w$ & 1042 & 232.9 & 1001 & vC18-O7 & 1001 & $v \mathrm{C} 18-\mathrm{O} 7$ \\
\hline $997 \mathrm{~s}$ & 994sh & $986 \mathrm{sh}$ & 1018 & 0.1 & 976 & $\rho^{\prime} \mathrm{CH}_{3}(\mathrm{C} 20), \rho^{\prime} \mathrm{CH}_{3}(\mathrm{C} 19)$ & 976 & $\rho^{\prime} \mathrm{CH}_{3}(\mathrm{C} 20), \rho^{\prime} \mathrm{CH}_{3}(\mathrm{C} 19)$ \\
\hline \multirow[t]{2}{*}{$971 \mathrm{~m}$} & $972 \mathrm{~m}$ & $976 \mathrm{~m}$ & 1018 & 0.5 & 975 & $\rho^{\prime} \mathrm{CH}_{3}(\mathrm{C} 21), \rho \mathrm{CH}_{3}(\mathrm{C} 22)$ & 975 & $\rho^{\prime} \mathrm{CH}_{3}(\mathrm{C} 21) \rho \mathrm{CH}_{3}(\mathrm{C} 22)$ \\
\hline & $958 \mathrm{sh}$ & $962 \mathrm{~s}$ & 1010 & 6.4 & 962 & $\tau \mathrm{wCH}_{2}(\mathrm{C} 15)$ & 962 & $\mathrm{vC} 12-\mathrm{O} 5, \tau \mathrm{wCH} 2(\mathrm{C} 15)$ \\
\hline 954sh & $951 \mathrm{~s}$ & $952 \mathrm{~m}$ & 1000 & 37.8 & 958 & $\rho \mathrm{CH}_{3}(\mathrm{C} 20) \rho \mathrm{CH}_{3}(\mathrm{C} 19)$ & 958 & $\rho \mathrm{CH}_{3}(\mathrm{C} 20)$ \\
\hline $945 \mathrm{~s}$ & & & 985 & 8.8 & 945 & $\rho \mathrm{CH}_{3}(\mathrm{C} 21), \rho^{\prime} \mathrm{CH}_{3}(\mathrm{C} 22)$ & 945 & $\rho \mathrm{CH}_{3}(\mathrm{C} 21) \rho^{\prime} \mathrm{CH}_{3}(\mathrm{C} 22)$ \\
\hline $920 w$ & $922 w$ & $926 \mathrm{~m}$ & 947 & 38.7 & 902 & $\rho \mathrm{CH}_{3}(\mathrm{C} 19) \rho \mathrm{CH}_{3}(\mathrm{C} 20)$ & 902 & $\rho \mathrm{CH}_{3}(\mathrm{C} 19)$ \\
\hline $901 \mathrm{~m}$ & $908 \mathrm{~m}$ & 896 sh & 939 & 8.5 & 896 & $\mathrm{oCH}_{3}\left(\mathrm{C}_{2} 1\right) .0^{\prime} \mathrm{CH}_{3}(\mathrm{C} 22)$ & 896 & ${ }_{0} \mathrm{CH}_{3}\left(\mathrm{C}_{2} 1\right) \mathrm{o}^{\prime} \mathrm{CH}_{3}(\mathrm{C} 22)$ \\
\hline $872 \mathrm{vs}$ & $876 \mathrm{~s}$ & $874 w$ & 936 & 0.4 & 892 & 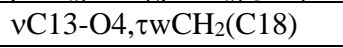 & 892 & $\tau \mathrm{wCH}_{2}(\mathrm{C} 18)$ \\
\hline $853 \mathrm{~s}$ & $858 \mathrm{~s}$ & $858 \mathrm{~s}$ & 928 & 88.9 & 887 & wagNH$_{2}$ & 887 & wagNH$_{2}$ \\
\hline $847 \mathrm{sh}$ & & & 893 & 75.6 & 862 & $\mathrm{vC} 16-\mathrm{O} 2$ & 862 & $\mathrm{vC} 16-\mathrm{O} 2$ \\
\hline $831 \mathrm{~m}$ & $837 \mathrm{w}$ & $842 w$ & 883 & 8.4 & 847 & $\mathrm{vC} 17-\mathrm{O} 5$ & 847 & $\mathrm{vC} 17-\mathrm{O} 5$ \\
\hline $816 \mathrm{~m}$ & $822 \mathrm{w}$ & $822 \mathrm{w}$ & 862 & 70.6 & 827 & vC16-O2,vC17-O5 & 827 & $v \mathrm{C} 16-\mathrm{O} 2, \mathrm{vC} 17-\mathrm{O} 5$ \\
\hline 796sh & $786 \mathrm{~s}$ & $801 \mathrm{~s}$ & 824 & 15.3 & 794 & $\mathrm{vC16-O4}$ & 794 & $\mathrm{vC16-O4}$ \\
\hline 780vs & & $783 \mathrm{vs}$ & 804 & 18.1 & 776 & $v \mathrm{C} 17-\mathrm{O} 6, \beta \mathrm{R}_{1}(\mathrm{~A} 3)$ & 776 & $\nu \mathrm{C} 17-\mathrm{O} 6, \beta \mathrm{R}_{1}(\mathrm{~A} 3)$ \\
\hline $780 \mathrm{vs}$ & & & 785 & 345.5 & 757 & vC13-O3 & 757 & $v \mathrm{C} 13-\mathrm{O} 3$ \\
\hline
\end{tabular}




\begin{tabular}{|c|c|c|c|c|c|c|c|c|}
\hline \multirow{2}{*}{\multicolumn{3}{|c|}{ Experimental }} & \multicolumn{6}{|c|}{ B3LYP/6-311++G** method $^{\text {a }}$} \\
\hline & & & \multirow[t]{2}{*}{ Calc. $^{\mathrm{b}}$} & \multirow[t]{2}{*}{ Int. $^{\mathrm{c}}$} & \multicolumn{2}{|c|}{$\mathrm{NH}_{2}\left(C_{2} V\right), \mathrm{SO}_{2}\left(C_{2} V\right)$} & \multicolumn{2}{|c|}{$\mathrm{NH}_{2}\left(C_{2} V\right), \mathrm{SO}_{3}\left(C_{3} V\right)$} \\
\hline ATR & IR & Raman & & & SQM $^{\mathrm{d}}$ & Assignments $^{\mathrm{a}}$ & $\mathrm{SQM}^{\mathrm{d}}$ & Assignments $^{\mathrm{a}}$ \\
\hline $747 \mathrm{~s}$ & $750 \mathrm{~m}$ & $750 \mathrm{vs}$ & 782 & 84.4 & 754 & $v \mathrm{~N} 10-\mathrm{S} 1$ & 754 & $v \mathrm{~N} 10-\mathrm{S} 1$ \\
\hline $730 \mathrm{sh}$ & & $733 \mathrm{vw}$ & 754 & 7.1 & 727 & $\mathrm{vC} 12-\mathrm{C} 14, \beta \mathrm{R}_{1}(\mathrm{~A} 1)$ & 727 & $\beta \mathrm{R}_{1}(\mathrm{~A} 1)$ \\
\hline $695 \mathrm{~s}$ & $700 w$ & $703 m$ & 735 & 5.2 & 714 & $\beta \mathrm{R}_{2}(\mathrm{~A} 3)$ & 714 & $\beta \mathrm{R}_{2}(\mathrm{~A} 3)$ \\
\hline $660 w$ & $668 \mathrm{vw}$ & $664 \mathrm{~m}$ & 697 & 2.2 & 674 & $\beta \mathrm{R}_{2}(\mathrm{~A} 2)$ & 674 & $\beta \mathrm{R}_{2}(\mathrm{~A} 2)$ \\
\hline $629 \mathrm{~m}$ & $639 w$ & 636vs & 679 & 81.1 & 654 & vO7-S1 & 654 & $\delta_{\mathrm{as}} \mathrm{SO}_{3}, v_{\mathrm{s}} \mathrm{SO}_{3}$ \\
\hline $629 \mathrm{~m}$ & $639 w$ & 636vs & 661 & 0.1 & 647 & $v \mathrm{C} 17-\mathrm{C} 22$ & 647 & $v \mathrm{C} 17-\mathrm{C} 22$ \\
\hline $568 \mathrm{vs}$ & $575 \mathrm{~s}$ & 576vs & 658 & 7.3 & 638 & $\beta \mathrm{R}_{1}(\mathrm{~A} 2)$ & 638 & $\beta \mathrm{R}_{1}(\mathrm{~A} 2)$ \\
\hline $546 w$ & $557 \mathrm{sh}$ & $548 \mathrm{~m}$ & 562 & 6.8 & 548 & $\tau \mathrm{wCC}(\mathrm{C} 16)$ & 548 & $\tau \mathrm{wCC}(\mathrm{C} 16)$ \\
\hline $524 \mathrm{~m}$ & $528 w$ & $528 \mathrm{~s}$ & 545 & 5.8 & 528 & $\delta \mathrm{C} 18 \mathrm{O} 7 \mathrm{~S} 1, \tau_{\mathrm{w}} \mathrm{SO}_{2}$ & 528 & $\delta \mathrm{C} 18 \mathrm{O} 7 \mathrm{~S} 1, \delta_{\mathrm{s}} \mathrm{SO}_{3}$ \\
\hline $513 \mathrm{~s}$ & $521 \mathrm{w}$ & $518 \mathrm{~m}$ & 527 & 4.8 & 515 & $\mathrm{\rho SO}_{2}$ & 515 & $\delta_{\mathrm{as}} \mathrm{SO}_{3}$ \\
\hline $498 \mathrm{~m}$ & $503 w$ & $500 \mathrm{~s}$ & 512 & 12.5 & 502 & $\tau \mathrm{wCC}(\mathrm{C} 17)$ & 502 & $\tau \mathrm{wCC}(\mathrm{C} 17)$ \\
\hline $498 \mathrm{~m}$ & $503 w$ & $500 \mathrm{~s}$ & 509 & 15.9 & 500 & $\tau \mathrm{wCC}(\mathrm{C} 16)$ & 500 & $\delta_{\mathrm{s}} \mathrm{SO}_{3}$ \\
\hline $490 \mathrm{~m}$ & & & 498 & 26.1 & 491 & $\tau \mathrm{wCC}{ }_{2}(\mathrm{C} 17), \tau \mathrm{wCC}(\mathrm{C} 16)$ & 491 & $\delta_{\mathrm{as}} \mathrm{SO}_{3}, \delta_{\mathrm{s}} \mathrm{SO}_{3}$ \\
\hline $452 \mathrm{sh}$ & $467 w$ & $455 \mathrm{w}$ & 480 & 12.0 & 469 & $\delta \mathrm{SO}_{2}$ & 469 & $\delta_{\mathrm{as}} \mathrm{SO}_{3}$ \\
\hline $434 \mathrm{sh}$ & & $427 \mathrm{~m}$ & 444 & 6.1 & 429 & wagCC $_{2}(\mathrm{C} 17) \rho^{\prime} \mathrm{C} 18-\mathrm{C} 13$ & 429 & $\operatorname{wagCC}_{2}(\mathrm{C} 17) \rho^{\prime} \mathrm{C} 18-\mathrm{C} 13$ \\
\hline $422 \mathrm{~m}$ & & & 433 & 13.7 & 417 & wagSO$_{2}$ & 417 & $\rho^{\prime} \mathrm{SO}_{3}$ \\
\hline $408 \mathrm{~m}$ & & & 418 & 2.6 & 405 & ButC11-C13 & 405 & ButC11-C13 \\
\hline \multirow[t]{26}{*}{$395 w$} & & $393 \mathrm{sh}$ & 410 & 0.7 & 401 & $\tau \mathrm{R}_{1}(\mathrm{~A} 1), \beta \mathrm{R}_{3}(\mathrm{~A} 1)$ & 401 & $\beta \mathrm{R}_{3}(\mathrm{~A} 1), \beta \mathrm{R}_{2}(\mathrm{~A} 1)$ \\
\hline & & $377 \mathrm{~s}$ & 387 & 2.9 & 379 & wagCC $_{2}(\mathrm{C} 16)$ & 378 & wagCC $2(\mathrm{C} 16)$ \\
\hline & & & 369 & 10.6 & 359 & ButC12-C14 & 359 & ButC12-C14 \\
\hline & & 349sh & 360 & 7.3 & 352 & $\delta \mathrm{O} 7 \mathrm{~S} 1 \mathrm{~N} 10$ & 352 & $\mathrm{\rho SO}_{3}$ \\
\hline & & $341 \mathrm{~s}$ & 347 & 1.0 & 341 & $\begin{array}{l}\delta \mathrm{CC}_{2}(\mathrm{C} 17), \quad \rho \mathrm{CC}_{2}(\mathrm{C} 17) \\
\tau \mathrm{R}_{1}(\mathrm{~A} 1)\end{array}$ & 341 & $\begin{array}{ll}\delta \mathrm{CC}_{2}(\mathrm{C} 17), & \rho \mathrm{CC}_{2}(\mathrm{C} 17) \\
\tau \mathrm{R}_{1}(\mathrm{~A} 1) & \\
\end{array}$ \\
\hline & & $326 \mathrm{~s}$ & 326 & 2.0 & 319 & $8 \mathrm{CC}_{2}(\mathrm{C} 16)$ & 319 & $\delta \mathrm{CC}_{2}(\mathrm{C} 16)$ \\
\hline & & $319 \mathrm{sh}$ & 319 & 8.7 & 309 & $\rho \mathrm{CC}_{2}(\mathrm{C} 16), \tau \mathrm{R}_{3}(\mathrm{~A} 1)$ & 309 & $\rho \mathrm{CC}_{2}(\mathrm{C} 16), \tau \mathrm{R}_{3}(\mathrm{~A} 1)$ \\
\hline & & & 311 & 3.2 & 303 & $\rho \mathrm{CC}_{2}(\mathrm{C} 16)$ & 303 & $\rho \mathrm{CC}_{2}(\mathrm{C} 16)$ \\
\hline & & $281 \mathrm{sh}$ & 296 & 13.5 & 280 & $\tau \mathrm{wNH}_{2}$ & 280 & $\tau \mathrm{wNH}_{2}$ \\
\hline & & 269vs & 278 & 1.2 & 264 & wagSO $_{2}, \tau \mathrm{wNH}_{2}$ & 264 & $\delta_{\mathrm{as}} \mathrm{SO}_{3}$ \\
\hline & & $234 v s$ & 255 & 0.3 & 239 & 8O7S1N10 & 239 & $\delta_{\mathrm{as}} \mathrm{SO}_{3}$ \\
\hline & & & 253 & 0.3 & 229 & $\tau_{\mathrm{w}} \mathrm{CH}_{3}(\mathrm{C} 21)$ & 229 & $\tau_{\mathrm{w}} \mathrm{CH}_{3}(\mathrm{C} 21)$ \\
\hline & & $226 \mathrm{sh}$ & 246 & 1.1 & 228 & $\tau_{\mathrm{w}} \mathrm{CH}_{3}(\mathrm{C} 19)$ & 228 & $\tau_{\mathrm{w}} \mathrm{CH}_{3}(\mathrm{C} 19)$ \\
\hline & & $212 \mathrm{sh}$ & 215 & 0.1 & 200 & $\tau_{\mathrm{w}} \mathrm{CH}_{3}(\mathrm{C} 21)$ & 200 & $\tau_{\mathrm{w}} \mathrm{CH}_{3}(\mathrm{C} 21)$ \\
\hline & & $200 \mathrm{sh}$ & 209 & 0.4 & 193 & $\tau_{\mathrm{w}} \mathrm{CH}_{3}(\mathrm{C} 20)$ & 193 & $\tau_{\mathrm{w}} \mathrm{CH}_{3}(\mathrm{C} 20)$ \\
\hline & & 190sh & 196 & 0.1 & 184 & $8 \mathrm{C} 18 \mathrm{O} 7 \mathrm{~S} 1$ & 184 & 8C18O7S1 \\
\hline & & & 190 & 0.6 & 177 & $\tau_{\mathrm{w}} \mathrm{CH}_{3}(\mathrm{C} 22)$ & 177 & $\tau_{\mathrm{w}} \mathrm{CH}_{3}(\mathrm{C} 22)$ \\
\hline & & $164 \mathrm{sh}$ & 180 & 11.6 & 173 & $\delta \mathrm{O} 7 \mathrm{C} 18 \mathrm{C} 13, \tau \mathrm{O} 7-\mathrm{S} 1$ & 173 & 8O7C18C13 \\
\hline & & & 131 & 4.2 & 123 & $\tau \mathrm{O} 7-\mathrm{S} 1, \rho \mathrm{C} 18-\mathrm{C} 13$ & 123 & $\tau_{\mathrm{w}} \mathrm{SO}_{3}, \rho \mathrm{C} 18-\mathrm{C} 13$ \\
\hline & & & 109 & 0.6 & 106 & $\tau \mathrm{R}_{1}(\mathrm{~A} 3), \tau \mathrm{R}_{3}(\mathrm{~A} 1)$ & 106 & $\tau \mathrm{R}_{1}(\mathrm{~A} 3), \tau \mathrm{R}_{3}(\mathrm{~A} 1)$ \\
\hline & & & 94 & 3.8 & 89 & $\tau \mathrm{R}_{1}(\mathrm{~A} 2), \tau \mathrm{R}_{2}(\mathrm{~A} 1)$ & 89 & $\tau \mathrm{R}_{1}(\mathrm{~A} 2), \tau \mathrm{R}_{2}(\mathrm{~A} 1)$ \\
\hline & & & 90 & 0.8 & 86 & $\tau \mathrm{R}_{2}(\mathrm{~A} 1)$ & 86 & $\tau \mathrm{R}_{2}(\mathrm{~A} 1)$ \\
\hline & & & 56 & 2.3 & 53 & $\tau \mathrm{R}_{2}(\mathrm{~A} 3)$ & 53 & $\tau \mathrm{R}_{2}(\mathrm{~A} 3)$ \\
\hline & & & 49 & 1.2 & 48 & $\tau \mathrm{R}_{1}(\mathrm{~A} 2), \tau \mathrm{R}_{2}(\mathrm{~A} 2)$ & 48 & $\tau \mathrm{R}_{1}(\mathrm{~A} 2), \tau \mathrm{R}_{2}(\mathrm{~A} 2)$ \\
\hline & & & 42 & 1.2 & 39 & $\tau \mathrm{C} 18-\mathrm{O} 7$ & 39 & $\tau \mathrm{C} 18-\mathrm{O} 7$ \\
\hline & & & 29 & 1.3 & 26 & $\tau_{\mathrm{w}} \mathrm{C} 18-\mathrm{C} 13$ & 26 & $\tau_{\mathrm{w}} \mathrm{C} 18-\mathrm{C} 13$ \\
\hline
\end{tabular}

Abbreviations: $v$, stretching; $\beta$, deformation in the plane; $\gamma$, deformation out of the plane; $\tau$, torsion; $\beta_{\mathrm{R}}$. deformation ring $\tau_{\mathrm{R}}$, torsion ring; $\rho$, rocking; $\tau \mathrm{w}$, twisting; $\delta$, deformation; a, antisymmetric; s, symmetric; $\left(\mathrm{A}_{1}\right)$, Ring R1; $\left(\mathrm{A}_{2}\right)$, Ring R2; ( $\left.\mathrm{A}_{3}\right)$, Ring $\mathrm{R} 3$; ${ }^{\mathrm{T}}$ This work, ${ }^{\mathrm{b}}$ Intensities in KM/Mole; ${ }^{\mathrm{C}}$ From B3LYP/6-311++G** method, ${ }^{\mathrm{d}}$ From scaled quantum mechanics force field.

3.6.1. Case 1. $\mathrm{C}_{2 \mathrm{~V}}$ symmetries for both $\mathrm{SO}_{2}$ and $\mathrm{NH}_{2}$ groups.

\subsubsection{1. $4000-2000 \mathrm{~cm}^{-1}$ region.}

In this region, for TPM are expected the antisymmetric and symmetric stretching modes corresponding to $\mathrm{NH}_{2}$, three $\mathrm{CH}_{3}$, and two $\mathrm{CH}_{2}$ groups and also to the aliphatic stretching 
modes of three $\mathrm{C}-\mathrm{H}$ groups. The two stretching modes of the $\mathrm{NH}_{2}$ group are predicted at 3430 and $3310 \mathrm{~cm}^{-1}$; hence, the shoulders and IR and Raman bands located between 3444 and 3376 $\mathrm{cm}^{-1}$ are assigned to these vibration modes. The assignments for the other two groups are perfectly detailed in Table 5. Note that the C14-H25 stretching mode is predicted to higher wavenumbers than the other ones, probably because it is next to the $\mathrm{O} 6$ atom belonging to the $\mathrm{R} 2$ ring. These assignments are in agreement with reported for compounds containing similar groups [18-21,33-35,37].

\subsubsection{2. $2000-1000 \mathrm{~cm}^{-1}$ region.}

In this region are expected the antisymmetric and symmetric stretching modes of $\mathrm{SO}_{2}$ groups, the $\mathrm{C}-\mathrm{C}$ and $\mathrm{C}-\mathrm{O}$ stretching modes, and the deformation, wagging, and rocking modes of $\mathrm{CH}_{3}$ and $\mathrm{CH}_{2}$ groups in addition to the deformation and rocking modes of $\mathrm{NH}_{2}$ and aliphatic $\mathrm{C}-\mathrm{H}$ groups. Thus, the IR and Raman bands at 1571 and $1574 \mathrm{~cm}^{-1}$ are assigned to $\mathrm{NH}_{2}$ deformation mode while the strong IR and Raman bands respectively at 1168 and $1177 \mathrm{~cm}^{-1}$ are assigned to corresponding rocking mode. The strong IR bands at 1348 and $1159 \mathrm{~cm}^{-1}$ are assigned to $\mathrm{SO}_{2}$ antisymmetric and symmetric modes as predicted by calculations and according to similar compounds [18-21]. The C-C stretching modes are predicted from 1240 to $647 \mathrm{~cm}^{-1}$ while the $\mathrm{C}-\mathrm{O}$ stretching modes from 1088 to $757 \mathrm{~cm}^{-1}$. Hence, the experimental bands observed in both spectra between 1240 and $647 \mathrm{~cm}^{-1}$ can be assigned to these vibration modes, as predicted by SQM calculations and as reported in the literature [33-35,37].

\subsubsection{3. $1000-20 \mathrm{~cm}^{-1}$ region.}

In Table 5 can be observed the expected vibration modes of TPM in this region. Thus, the deformation, wagging, rocking, and twisting modes of $\mathrm{SO}_{2}$ and wagging and twisting modes of the $\mathrm{NH}_{2}$ group are predicted in this region. On the other hand, the N10-S1 and O7S1 stretching modes corresponding to the sulfamate group of TPM are also expected in this region. Here, the IR and Raman bands at 467, 422, 513, and $524 \mathrm{~cm}^{-1}$ are assigned respectively to deformation, wagging, rocking, and twisting modes of the $\mathrm{SO}_{2}$ group while the bands at 853 and $281 \mathrm{~cm}^{-1}$ are assigned to wagging and twisting modes of $\mathrm{NH}_{2}$ group. The SQM calculations predict the wagging $\mathrm{SO}_{2}$ mode coupled with the twisting $\mathrm{NH}_{2}$ mode at $264 \mathrm{~cm}^{-1}$, for which the very strong Raman band at $269 \mathrm{~cm}^{-1}$ can also be assigned to those two vibration modes. The strong and medium intensity bands at 747 and $629 \mathrm{~cm}^{-1}$ can be assigned respectively to the N10-S1 and O7-S1 stretching modes, as predicted by the SQM calculations. The vibration modes of six and five-membered rings are assigned according to the theoretical calculations and be reported for compounds with similar rings [18-21,33-35,37].

3.6.2. Case 2. $\mathrm{C}_{3 \mathrm{~V}}$ and $\mathrm{C}_{2 \mathrm{v}}$ symmetries for both $\mathrm{SO}_{3}$ and $\mathrm{NH}_{2}$ groups.

\subsubsection{1. $4000-2000 \mathrm{~cm}^{-1}$ region.}

In this region, the vibrational assignments for TPM are exactly similar for those proposed for case 1 , as observed in Table 5 .

\subsubsection{2. $2000-1000 \mathrm{~cm}^{-1}$ region.}

In this region and from 2000 to $1200 \mathrm{~cm}^{-1}$, the assignments for case 2 are the same that for case 1 and, from 1186 to $1039 \mathrm{~cm}^{-1}$, some assignments have changed. Thus, the strong IR 
band at $1177 \mathrm{~cm}^{-1}$ is assigned to $\mathrm{C} 13-\mathrm{O} 4$ stretching mode, while the strong IR band at 1159 $\mathrm{cm}^{-1}$ can be simultaneously assigned to $\mathrm{C} 13-\mathrm{C} 11$ and $\mathrm{C} 14-\mathrm{C} 15$ stretching modes and to antisymmetric and symmetric stretching modes of the $\mathrm{SO}_{3}$ group. Then, the strong IR band at $1039 \mathrm{~cm}^{-1}$ is assigned to the $\mathrm{C} 14-\mathrm{O} 6$ and $\mathrm{C} 15-\mathrm{O} 3$ stretching modes.

\subsubsection{3. $1000-20 \mathrm{~cm}^{-1}$ region.}

In this region are observed the higher variations in the assignments de some groups for case 2. Hence, some rocking modes of $\mathrm{CH}_{3}$ groups and twisting mode of $\mathrm{CH}_{2}(\mathrm{C} 18)$ are predicted by calculations as pure modes, without coupling, while other vibration modes from 654 up to $349 \mathrm{~cm}^{-1}$ and from 264 to $239 \mathrm{~cm}^{-1}$ change completely with the case 2 is considered, as detailed in Table 5. The expected assignments of deformations and torsions of six and five members' rings were performed according to the SQM calculations and to assignments reported for compounds with similar rings [18-21,33-35,37,38].

The two proposed assignments for TPM considering both harmonic force fields are well represented because the calculated harmonic vibrational frequencies are consistent with the experimental IR and Raman spectra in the solid phase.

Table 6. Scaled internal force constants for topiramate in gas phase and aqueous solution by using the B3LYP/6-311++G** method.

\begin{tabular}{l|l|l|l|l}
\hline \multirow{2}{*}{ Force constant } & \multicolumn{4}{|c}{ B3LYP/6-311++G** method $^{\mathbf{a}}$} \\
\cline { 2 - 5 } & \multicolumn{4}{|c}{ Camphor } \\
\cline { 2 - 5 } & $\mathrm{NH}_{2}\left(C_{2 V}\right), \mathrm{SO}_{2}\left(C_{2 V}\right)$ & $\mathrm{NH}_{2}\left(C_{2 V}\right), \mathrm{SO}_{3}\left(C_{3 V}\right)$ \\
\cline { 2 - 5 } & $\mathrm{Gas}$ & $\mathrm{PCM}$ & $\mathrm{Gas}$ & $\mathrm{PCM}$ \\
\hline$f(\nu C-H)$ & 4.71 & 4.71 & 4.71 & 4.71 \\
\hline$f(v C-O)$ & 4.46 & 4.46 & 4.46 & 4.46 \\
\hline$f(v S=O)$ & 9.26 & 9.26 & 7.32 & 7.32 \\
\hline$f(v S-O)$ & 3.43 & 3.43 & & \\
\hline$f\left(v \mathrm{NH}_{2}\right)$ & 6.31 & 6.31 & 6.31 & 6.31 \\
\hline$f\left(v C H_{2}\right)$ & 4.92 & 4.92 & 4.92 & 4.92 \\
\hline$f\left(v C H_{3}\right)$ & 4.94 & 4.94 & 4.94 & 4.94 \\
\hline$f\left(\delta \mathrm{NH}_{2}\right)$ & 0.63 & 0.63 & 0.63 & 0.63 \\
\hline$f\left(\delta \mathrm{SO}_{2}\right)$ & 1.80 & 1.80 & 1.76 & 1.76 \\
\hline$f\left(\delta \mathrm{CH}_{2}\right)$ & 0.78 & 0.78 & 0.78 & 0.78 \\
\hline$f\left(\delta \mathrm{CH}_{3}\right)$ & 0.54 & 0.54 & 0.54 & 0.54 \\
\hline
\end{tabular}

Units are mdyn $\AA^{-1}$ for stretching and mdyn $\AA \operatorname{rad}^{-2}$ for angle deformations; ${ }^{\text {a This work }}$

\subsection{Force fields.}

The scaled force constants of TPM in both media were determined for the two proposed harmonic force fields by using the B3LYP/6-311++G** method, the SQMFF methodology, and the Molvib program [11-13]. These force constants are shown in Table 6.

When the values for each case are compared in both media, it is observed that all force constants do not change; however, when the force constants for the case 1 are compared with the corresponding to case 2 we observed that only the $f(v \mathrm{~S}=O)$ and $f\left(\delta \mathrm{SO}_{2}\right)$ force constants values have changed, as expected. Such observation is justified because, in case 1, the sulfamate group was considered as an $\mathrm{SO}_{2}$ group where the two involved $\mathrm{S}=\mathrm{O}$ bonds have double bonds characteristics, while in case 2, that $\mathrm{SO}_{3}$ group has three $\mathrm{S}-\mathrm{O}$ bonds with characteristics of simple bonds. 
Hence, lower values are expected for those two force constants in case 2. On the other hand, the $f\left(v_{S_{3}}\right)$ and $f\left(\delta \mathrm{SO}_{3}\right)$ force constants values observed for the $\mathrm{SO}_{3}$ group of TPM are in agreement with those observed for the sulfonate group of 1-Butyl-3-methylimidazolium trifluoromethanesulfonate ionic liquid, with values of 7.63 mdyn $\AA^{-1}$ and 1.62 mdyn $\AA \mathrm{rad}^{-2}$, respectively [18]. Whereas the $f(v S=O)$ and $f\left(\delta S O_{2}\right)$ force constants values of TPM are in agreement with the reported for the neutral form of cyclamic acid (9.02 mdyn $\AA^{-1}$ and 1.87 mdyn $\left.\AA \operatorname{rad}^{-2}\right)$ [19]. The $f\left(v N H_{2}\right)$ and $f\left(\delta \mathrm{NH}_{2}\right)$ force constants obtained for TPM with both force fields present approximately similar values to the reported for the antiviral cidofovir agent (6.79 mdyn $\AA^{-1}$ and 0.70 mdyn $\left.\AA \mathrm{rad}^{-2}\right)$ [33]. Finally, the $f\left(\mathrm{vCH}_{3}\right)$ and $f\left(\mathrm{vCH}_{2}\right)$ force constants for both TPM cases show good concordances with the reported for the free base of promethazine (4.82 and 4.74 mdyn $\left.\AA^{-1}\right)$ [37].

\subsection{Ultraviolet-visible spectra.}

The electronic spectra of TPM in aqueous solution was predicted by using the B3LYP/6-311++G** method and TD-DFT calculations with the Gaussian 09 program [10]. The same presents an intense band in c.a. $185 \mathrm{~nm}$ and can be seen in Figure 7 [39]. Experimentally TPM cannot be analyzed by ultraviolet spectroscopic methods, as mentioned by Khalil et al. because it species does not contain any chromospheres that could yield absorbance bands above $190 \mathrm{~nm}$ [7]. That strong band predicted by using the B3LYP/6$311++\mathrm{G}^{* *}$ method could be associated with $n \rightarrow \sigma^{*}$ interactions, as supported by NBO calculations.

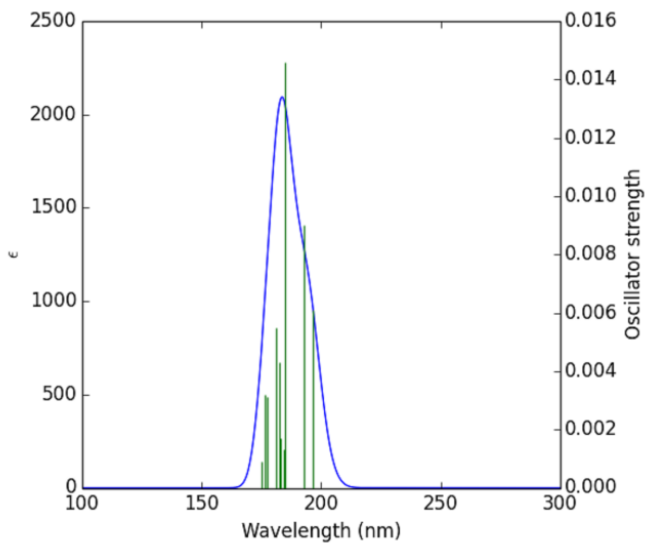

Figure 7. Predicted Ultraviolet-visible spectra of topiramate in aqueous solution by using the B3LYP/6$311++\mathrm{G}^{* *}$ method.

\section{Conclusions}

The theoretical structures of topiramate in the gas phase and aqueous solution have been determined by using the hybrid B3LYP/6-311++G** method. Very good concordances were found between the theoretical structures and the corresponding experimental reported. Thus, the fused five-membered ring in topiramate produces that the pyranose ring adopts distorted twist-boat conformation, as was experimentally observed. The calculated N10-O3 distance between the $\mathrm{N}$ atom and the $\mathrm{O} 3$ pyranose ring oxygen atom (3.349 and $3.867 \AA$ ), different from the experimental value ( $5.965 \AA$ ), could justify the biological activity of TPM because the N10O3 distance connects the hydrophilic part with the corresponding hydrophobic one. In solution, all calculations were performed with the SCRF method and the IEFPCM and SMD models. 
The corrected solvation energy value for topiramate in aqueous solution by total nonelectrostatic terms and by ZPVE is $-1066.10 \mathrm{~kJ} / \mathrm{mol}$.

The bond orders have evidenced that the three $\mathrm{O}$ atoms are not linked to the same form to $S$ atom. Hence, the $S$ atom of TPM is practically tetra-coordinate in both media, as evidenced by the high negative MK and NPA charges on the $\mathrm{O}$ atoms linked to it.

The AIM study supports the higher stability of TPM in the gas phase while the NBO study suggests the higher stability in solution.

The studies by using the frontier orbitals suggest that TPM is slightly most reactive in solution.

The complete assignments of 123 vibration modes of TPM are reported with the B3LYP/6-311++ $\mathrm{G}^{* *}$ level of theory and taking into account two harmonic force fields. In one case, the normal internal coordinates of both $\mathrm{SO}_{2}$ and $\mathrm{NH}_{2}$ groups have been considered with $C_{2 V}$ symmetries, and, in the other one, the $\mathrm{NH}_{2}$ and $\mathrm{SO}_{3}$ groups present $C_{2 V}$ and $C_{3 V}$ symmetries, respectively. The scaled force constant for both cases is reported for the first time.

Comparisons of predicted ${ }^{1} \mathrm{H}$ - and ${ }^{13} \mathrm{C}-\mathrm{NMR}$ spectra with the corresponding experimental ones reveal very good concordances.

\section{Funding}

This research received no external funding.

\section{Acknowledgments}

This work was supported with grants from CIUNT Project No 26/D608 (Consejo de Investigaciones, Universidad Nacional de Tucumán).

\section{Conflicts of Interest}

The authors declare no conflict of interest.

\section{Supporting Information Available}

\section{Tables from S1-S2 and Figures S1-S7.}

\section{References}

1. Kubicki, M.; Codding, P.W.; Litster, S.A.; Szkaradziñska, M.B.; Bassyouni, H.A.R. Pyranose sulfamates: conformation and hydrogen bonding. J. Mol. Struct. 1999, 474, 255-265, https://doi.org/10.1016/S00222860(98)00578-X.

2. Abbate, F.; Winum, J-Y; Potter, B.V.L.; Casini, A.; Montero, J-L; Scozzafava, A.; Supuran, C.T. Carbonic anhydrase inhibitors: X-ray crystallographic structure of the adduct of human isozyme II with EMATE, a dual inhibitor of carbonic anhydrases and steroid sulfatase. Bioorganic \& Medicinal Chemistry Letters 2004, 14, 231-234, https://doi.org/10.1016/j.bmcl.2003.11.014.

3. Abbate, F.; Coetzee, A.; Casini, A.; Ciattini, S.; Scozzafavac, A.; Supuran, C.T. Carbonic anhydrase inhibitors: X-ray crystallographic structure of the adduct of human isozyme II with the antipsychotic drug sulpiride. Bioorganic \& Medicinal Chemistry Letters 2004, 14, 337-341, https://doi.org/10.1016/j.bmcl.2003.09.064.

4. Sena Jr., D.M.; Freire, P.T.C.; Filho, J.M.; Melo, F.E.A.; Pontes, F.M.; Longo, E.; Ferreirae, O.P.; Alves, O.L. Vibrational and Thermal Properties of Crystalline Topiramate. J. Braz. Chem. Soc. 2008, 19, 16071613, https://doi.org/10.1590/S0103-50532008000800022.

5. Ghiasi, M.; Oskouie, A.A.; Saeidian, H. Dynamic stereochemistry of topiramate (anticonvulsant drug) in solution: theoretical approaches and experimental validation. Carbohydrate Research 2012, 348, 47-54, https://doi.org/10.1016/j.carres.2011.11.010. 
6. Ghiasi, M.; Kamalinahad, S. Conformational Analysis of Topiramate and Related Anion in the Solution and Interaction Between the Most Stable Conformer of Topiramate with Active Center of Carbonic Anhydrase Enzyme. Journal of Carbohydrate Chemistry 2015, 34, 80-102, http://dx.doi.org/10.1080/07328303.2015.1009090.

7. Khalil, N.Y.; AlRabiah, H.K.; AL Rashoud, S.S.; Bari, A.; Wani, T.A. Topiramate, Comprehensive profile, Profiles of Drug Substances, Excipients, and Related Methodology. Elsevier Inc. 2019, 44, https://doi.org/10.1016/bs.podrm.2018.11.005.

8. Becke, A.D. Density-functional exchange-energy approximation with correct asymptotic behavior. Phys. Rev. 1988, A38, 3098-3100, https://doi.org/10.1103/PhysRevA.38.3098.

9. Lee, C.; Yang, W.; Parr, R.G. Development of the Colle-Salvetti correlation-energy formula into a functional of the electron density. Phys. Rev. 1988, B37, 785-789, https://doi.org/10.1103/PhysRevB.37.785.

10. Frisch, M.J.; Trucks, G.W.; Schlegel, H.B.; Scuseria, G.E.; Robb, M.A.; Cheeseman, J.R.; Scalmani, G.; Barone, V.; Mennucci, B.; Petersson, G.A.; Nakatsuji, H.; Caricato, M.; Li, X.; Hratchian, H.P.; Izmaylov, A.F.; Bloino, J.; Zheng, G.; Sonnenberg, J.L.; Hada, M.; Ehara, M.; Toyota, K.; Fukuda, R.; Hasegawa, J.; Ishida, M.; Nakajima, T.; Honda, Y.; Kitao, O.; Nakai, H.; Vreven, T.; Montgomery, J.A.; Peralta, J.E.; Ogliaro, F.; Bearpark, M.; Heyd, J.J.; Brothers, E.; Kudin, K.N.; Staroverov, V.N.; Kobayashi, R.; Normand, J.; Raghavachari, K.; Rendell, A.; Burant, J.C.; Iyengar, S.S.; Tomasi, J.; Cossi, M.; Rega, N.; Millam, J.M.; Klene, M.; Knox, J.E.; Cross, J.B.; Bakken, V.; Adamo, C.; Jaramillo, J.; Gomperts, R.; Stratmann, R.E.; Yazyev, O.; Austin, A.J.; Cammi, R.; Pomelli, C.; Ochterski, J.W.; Martin, R.L.; Morokuma, K.; Zakrzewski, V.G.; Voth, G.A.; Salvador, P.; Dannenberg, J.J.; Dapprich, S.; Daniels, A.D.; Farkas, O.; Foresman, J.B.; Ortiz, J.; Cioslowski, J.; Fox, D.J. Gaussian, Inc., Wallingford CT, 2009.

11. Pulay, P.; Fogarasi, G.; Pongor, G.; Boggs, J.E.; Vargha, A. Combination of theoretical ab initio and experimental information to obtain reliable harmonic force constants. Scaled quantum mechanical (QM) force fields for glyoxal, acrolein, butadiene, formaldehyde, and ethylene. J. Am. Chem. Soc. 1983, 105, 70377047, https://doi.org/10.1021/ja00362a005.

12. Rauhut, G.; Pulay, P. Transferable Scaling Factors for Density Functional Derived Vibrational Force Fields. J. Phys. Chem. 1995, 99, 3093-3100, https://doi.org/10.1021/j100010a019

13. Sundius, T. Scaling of ab-initio force fields by MOLVIB. Vib. Spectrosc. 2002, 29, 89-95, https://doi.org/10.1016/S0924-2031(01)00189-8.

14. Miertus, S.; Scrocco, E.; Tomasi, J. Electrostatic interaction of a solute with a continuum. Chem. Phys. 1981, 55, 117-129, https://doi.org/10.1016/0301-0104(81)85090-2.

15. Tomasi, J.; Persico, J. Molecular Interactions in Solution: An Overview of Methods Based on Continous Distributions of the Solvent. Chem. Rev. 1994, 94, 2027-2094, https://doi.org/10.1021/cr00031a013.

16. Marenich, A.V.; Cramer, C.J.; Truhlar, D.G. Universal solvation model based on solute electron density and a continuum model of the solvent defined by the bulk dielectric constant and atomic surface tensions. J. Phys. Chem. 2009, B113, 6378-6396, https://doi.org/10.1021/jp810292n.

17. Paar, R.G.; Pearson, R.G. Absolute hardness: companion parameter to absolute electronegativity. J. Am. Chem. Soc. 1983, 105, 7512-7516, https://doi.org/10.1021/ja00364a005.

18. Kausteklis, J.; Aleksa, V.; Iramain, M.A.; Brandán, S.A. DFT study and vibrational assignment of 1-Butyl3-methylimidazolium trifluoromethanesulfonate ionic liquid by using the FT-Raman spectrum. J Mol. Struct. 2019, 1175, 663-676. https://doi.org/10.1016/j.molstruc.2018.08.014.

19. Brizuela, A.B.; Raschi, A.B.; Castillo, M.V.; Davies, L.; Romano, E.; Brandán, S.A. Structural and vibrational investigation on species derived from cyclamic acid in aqueous solution by using HATR and Raman spectroscopies and SCRF calculations. J. Mol. Struct. 2014, 1074, 144-156, http://dx.doi.org/10.1016/j.molstruc.2014.05.019.

20. Ben M'leh, C.; Brandán, S.A.; Issaoui, N.; Roisnel, T.; Marouani, H. Synthesis, molecular structure, vibrational and theoretical studies of a new non-centrosymmetric organic sulphate with promising NLO properties. J Mol. Struct. 2018, 1171, 771-785, https://doi.org/10.1016/j.molstruc.2018.06.041.

21. Noureddine, O.; Gatfaoui, S.; Brandán, S.A.; Marouani, H.; Issaoui, N. Structural, docking and spectroscopic studies of a new piperazine derivative, 1-Phenylpiperazine-1,4-diium-bis (hydrogen sulfate). J Mol. Struct. 2020, 1202, https://doi.org/10.1016/j.molstruc.2019.127351.

22. Experimental available ATR, IR and Raman spectra of topiramate from: https://spectrabase.com/spectrum/

23. Keresztury, G.; Holly, S.; Besenyei, G.; Varga, J.; Wang, A.Y.; Durig, J.R. Vibrational spectra of monothiocarbamates-II. IR and Raman spectra, vibrational assignment, conformational analysis and $a b$ initio calculations of $S$-methyl- $N, N$-dimethylthiocarbamate. Spectrochim. Acta 1993, 49A, 2007-2026, https://doi.org/10.1016/S0584-8539(09)91012-1.

24. Michalska, D.; Wysokinski, R. The prediction of Raman spectra of platinum(II) anticancer drugs by density functional theory. Chemical Physics Letters 2005, 403, 211-217, https://doi.org/10.1016/j.cplett.2004.12.096.

25. Glendening, E.; Badenhoop, J.K.; Reed, A.D.; Carpenter, J.E.; Weinhold, F. NBO 3.1. Theoretical Chemistry Institute, University of Wisconsin; Madison, WI, 1996.

26. Bader, R.F.W. Atoms in Molecules, A Quantum Theory. Oxford University Press, Oxford, 1990. 
27. Biegler-Köning, F.; Schönbohm, J.; Bayles, D. AIM2000; A Program to Analyze and Visualize Atoms in Molecules. J. Comput. Chem. 2001, 22, http://dx.doi.org/10.1002/1096987X(20010415)22:5\%3C545::AID-JCC1027\%3E3.0.CO;2-Y

28. Besler, B.H.; Merz, J.K.M.; Kollman, P.A. Atomic charges derived from semiempirical methods. J. Comp. Chem. 1990, 11, 431-439, https://doi.org/10.1002/jcc.540110404.

29. Nielsen, A.B.; Holder, A.J. Gauss View 3.0. User's Reference. Gaussian Inc., Pittsburgh, PA, $2000-2003$.

30. Ugliengo, P. Moldraw Program, University of Torino, Dipartimento Chimica IFM, Torino, Italy, 1998.

31. Ditchfield, R. Self-consistent perturbation theory of diamagnetism. I. A gage-invariant LCAO (linear combination of atomic orbitals) method for NMR chemical shifts. Mol Phys. 1974, 27, 714-722.

32. Iramain, M.A.; Brandán, S.A. Structural and vibrational study on the acid, hexa-hydrated and anhydrous trisodic salts of antiviral drug Foscarnet. Drug Designing \& Intellectual Properties International Journal 2018, 1, 1-17, http://dx.doi.org/10.32474/DDIPIJ.2018.01.000114.

33. Romani, D.; Brandán, S.A. Effect of the side chain on the properties from cidofovir to brincidofovir, an experimental antiviral drug against to Ebola virus disease. Arabian Journal of Chemistry 2019, 12, 29592972, http://dx.doi.org/10.1016/j.arabjc.2015.06.030.

34. Brandán, S.A. Understanding the potency of heroin against to morphine and cocaine. International Journal of Science and Research Methodology, 2018, 12, 97-140.

35. Rudyk, R.A.; Checa, M.A.; Catalán, C.A.N.; Brandán, S.A. Structural, FT-IR, FT-Raman and ECD spectroscopic studies of free base, cationic and hydrobromide species of scopolamine alkaloid. J. Mol. Struct. 2019, 1180, 603-617, https://doi.org/10.1016/j.molstruc.2018.12.040

36. Meldrum, B.S. Update on the mechanism of action of antiepileptic drugs. Epilepsia 1996, 37, S4-S11.

37. Manzur, M.E.; Brandán, S.A. S(-) and R(+) Species Derived from Antihistaminic Promethazine Agent: Structural and Vibrational Studies. Heliyon 2019, 5, https://doi.org/10.1016/j.heliyon.2019.e02322.

38. Brandán, S.A. Structural and Vibrational Studies of Equilenin, Equilin and Estrone Steroids. Biointerface Research in Applied Chemistry 2019, 9, 4502-4516, https://doi.org/10.33263/BRIAC96.502516.

39. O’ Boyle, N.M.; Tenderholt, A.L.; Langner, K.M. GaussSum 3.0 program. J. Comp. Chem. 2008, 29, 839845. 


\section{Supplementary files}

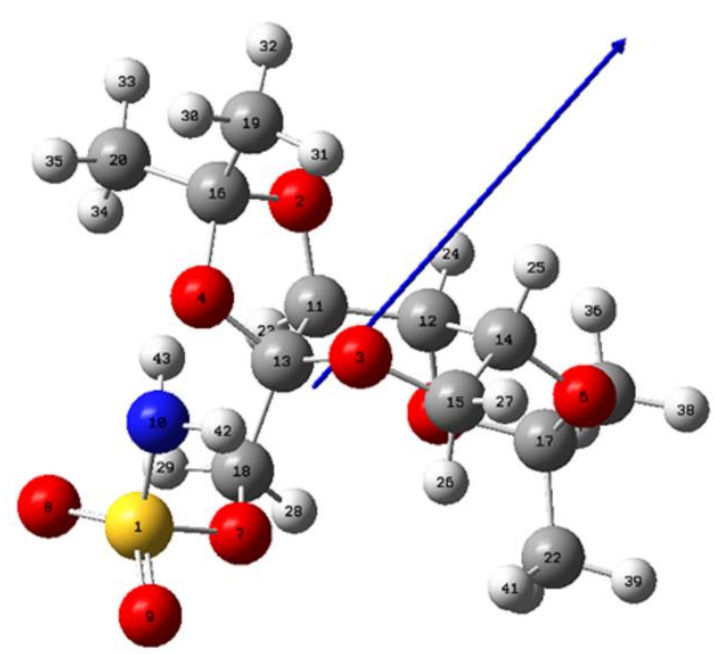

Gas Phase

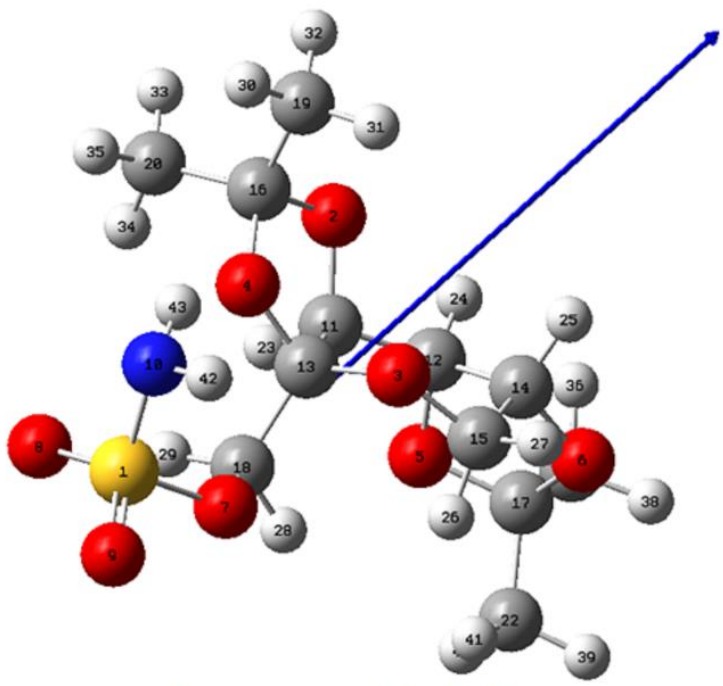

Aqueous Solution

Figure S1. Orientations and directions of dipole moment vectors predicted for topiramate in both media by using the B3LYP/6-311++G** level of theory

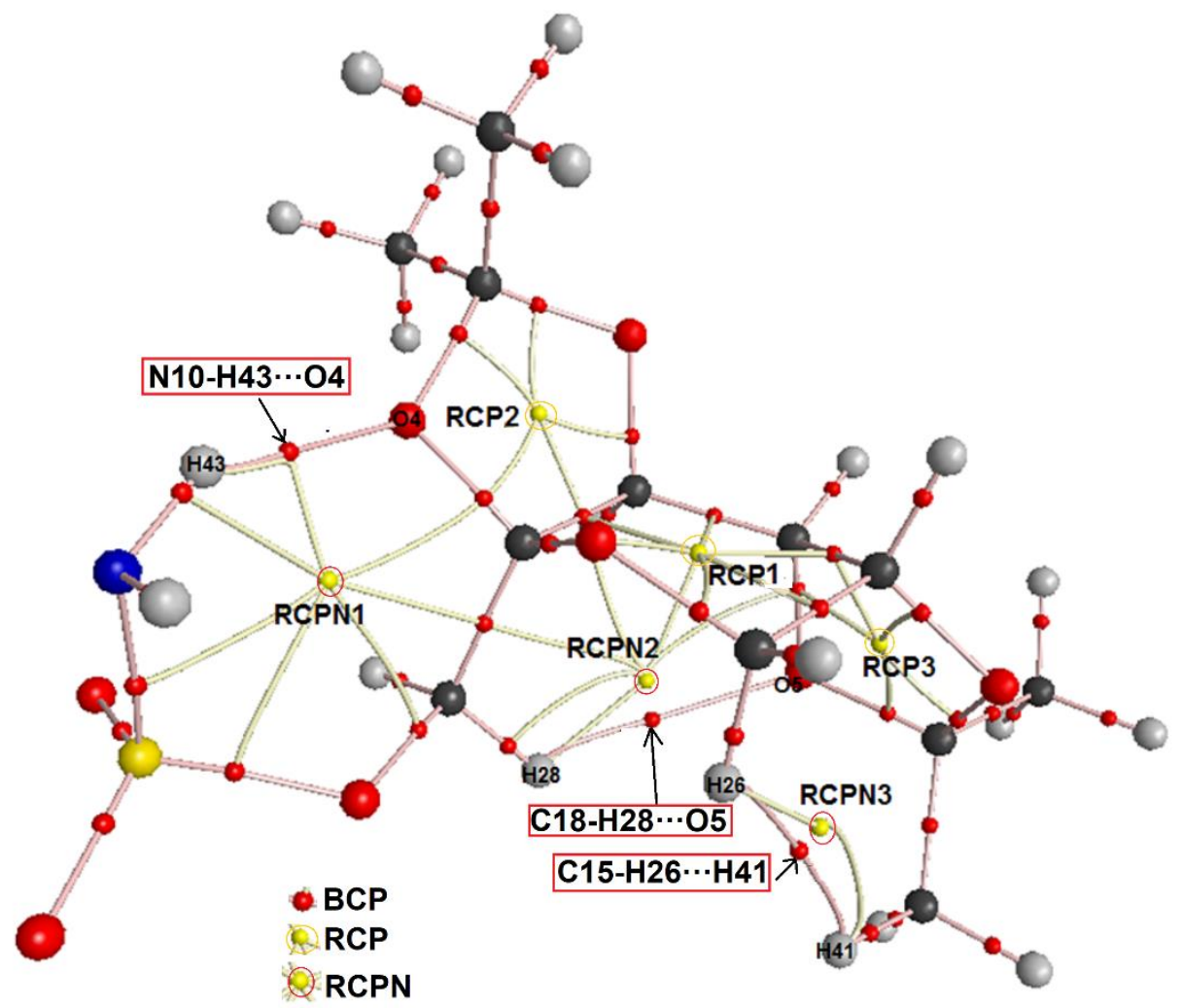

Figure S2. Molecular graphics of topiramate in gas phase showing their three $\mathrm{H}$ bonds interactions, three new RCPN and three RCPs by using the B3LYP/6-311++G** method. 
Table S1. Mulliken, Merz-Kollman and NPA charges (a.u.), molecular electrostatic potentials (MEP) (a.u.) and bond orders, expressed as Wiberg indexes of topiramate in gas phase and aqueous solution by using B3LYP/6$311++\mathrm{g}(\mathrm{d}, \mathrm{p})$ calculations.

\begin{tabular}{|c|c|c|c|c|c|c|c|c|c|c|}
\hline \multicolumn{11}{|c|}{ Topiramate } \\
\hline & GAS & & & & & PCM & & & & \\
\hline Atoms & MK & Mulliken & NPA & MEP & $\mathrm{BO}$ & MK & Mulliken & NPA & MEP & $\mathrm{BO}$ \\
\hline $1 \mathrm{~S}$ & 1,1873 & 0,4537 & 2,3709 & $-58,9862$ & 4,2805 & 1,2095 & 0,4559 & 2,3860 & $-58,9885$ & 4,2841 \\
\hline 20 & $-0,6749$ & 0,1340 & $-0,6118$ & $-22,3332$ & 1,9999 & $-0,6336$ & 0,1189 & $-0,6086$ & $-22,3314$ & 2,0013 \\
\hline $3 \mathrm{O}$ & $-0,3563$ & 0,1039 & $-0,6170$ & $-22,3358$ & 2,0136 & $-0,3728$ & 0,0027 & $-0,6069$ & $-22,3408$ & 2,0152 \\
\hline $4 \mathrm{O}$ & $-0,4780$ & 0,0982 & $-0,6409$ & $-22,3269$ & 2,0143 & $-0,4826$ & 0,0427 & $-0,6508$ & $-22,3275$ & 2,0116 \\
\hline $5 \mathrm{O}$ & $-0,5645$ & 0,1269 & $-0,6225$ & $-22,3355$ & 1,9912 & $-0,6098$ & 0,1300 & $-0,6237$ & $-22,3368$ & 1,9865 \\
\hline 60 & $-0,6202$ & 0,0680 & $-0,6190$ & $-22,3453$ & 1,9873 & $-0,6150$ & 0,0517 & $-0,6227$ & $-22,3473$ & 1,9790 \\
\hline $7 \mathrm{O}$ & $-0,4034$ & 0,0124 & $-0,7370$ & $-22,3182$ & 1,8957 & $-0,4192$ & $-0,0312$ & $-0,7421$ & $-22,3177$ & 1,8982 \\
\hline 80 & $-0,4858$ & $-0,2251$ & $-0,8889$ & $-22,3694$ & 1,6898 & $-0,5088$ & $-0,2523$ & $-0,9018$ & $-22,3772$ & 1,6687 \\
\hline 90 & $-0,4976$ & $-0,0949$ & $-0,8719$ & $-22,3730$ & 1,7055 & $-0,5164$ & $-0,1375$ & $-0,8849$ & $-22,3828$ & 1,6814 \\
\hline $10 \mathrm{~N}$ & $-0,8528$ & $-0,5071$ & $-1,0126$ & $-18,3631$ & 2,7704 & $-0,8455$ & $-0,5364$ & $-1,0169$ & $-18,3611$ & 2,7736 \\
\hline $11 \mathrm{C}$ & 0.4848 & -0.1045 & 0.0868 & -14.6825 & 3.8816 & 0.2683 & -0.1139 & 0.0861 & -14.6810 & 3.8801 \\
\hline $12 \mathrm{C}$ & 0.0112 & -0.3010 & 0.0977 & -14.6882 & 3.8778 & 0.1444 & -0.3580 & 0.0990 & -14.6876 & 3.8791 \\
\hline $13 \mathrm{C}$ & -0.0558 & -0.7853 & 0.5505 & -14.6308 & 3.8643 & 0.0136 & -0.0491 & 0.5493 & -14.6296 & 3.8702 \\
\hline $14 \mathrm{C}$ & 0.3559 & -0.3261 & 0.0928 & -14.6957 & 3.8783 & 0.2169 & -0.3110 & 0.0933 & -14.6968 & 3.8782 \\
\hline $15 \mathrm{C}$ & 0.0570 & -0.0443 & -0.0498 & -14.7049 & 3.8277 & 0.1658 & -0.0644 & -0.0475 & -14.7061 & 3.8309 \\
\hline $16 \mathrm{C}$ & 1.0252 & -0.8750 & 0.6002 & -14.6365 & 3.8172 & 1.0352 & -0.9306 & 0.6029 & -14.6346 & 3.8178 \\
\hline $17 \mathrm{C}$ & 0.9551 & -0.8033 & 0.5907 & -14.6442 & 3.8308 & 0.9798 & -0.8244 & 0.5936 & -14.6445 & 3.8310 \\
\hline $18 \mathrm{C}$ & 0.1070 & -0.4172 & -0.0801 & -14.6908 & 3.8116 & 0.1569 & -0.7519 & -0.0641 & -14.6886 & 3.8081 \\
\hline $19 \mathrm{C}$ & -0.5031 & -0.1879 & -0.6058 & -14.7661 & 3.8868 & -0.5556 & -0.1718 & -0.6008 & -14.7630 & 3.8858 \\
\hline $20 \mathrm{C}$ & -0.5534 & -0.2010 & -0.6028 & -14.7648 & 3.8896 & -0.5450 & -0.1920 & -0.6089 & -14.7631 & 3.8896 \\
\hline $21 \mathrm{C}$ & -0.5203 & -0.2614 & -0.6079 & -14.7683 & 3.8928 & -0.4367 & -0.2458 & -0.6083 & -14.7684 & 3.8925 \\
\hline $22 \mathrm{C}$ & -0.6958 & -0.1166 & -0.5981 & -14.7673 & 3.8906 & -0.6988 & -0.0923 & -0.5984 & -14.7673 & 3.8909 \\
\hline $23 \mathrm{H}$ & 0.0307 & 0.2331 & 0.1951 & -1.0825 & 0.9656 & 0.0798 & 0.2421 & 0.1955 & -1.0806 & 0.9656 \\
\hline $24 \mathrm{H}$ & 0.1027 & 0.2250 & 0.1946 & -1.0908 & 0.9659 & 0.1016 & 0.2207 & 0.1948 & -1.0908 & 0.9659 \\
\hline $25 \mathrm{H}$ & 0.0315 & 0.2302 & 0.1994 & -1.0932 & 0.9631 & 0.0649 & 0.2303 & 0.2005 & -1.0934 & 0.9626 \\
\hline $26 \mathrm{H}$ & 0.0729 & 0.2121 & 0.1777 & -1.0968 & 0.9725 & 0.0453 & 0.2312 & 0.1719 & -1.0961 & 0.9744 \\
\hline $27 \mathrm{H}$ & 0.0860 & 0.2078 & 0.2007 & -1.0937 & 0.9619 & 0.0707 & 0.2094 & 0.2029 & -1.0945 & 0.9610 \\
\hline $28 \mathrm{H}$ & 0.1022 & 0.2007 & 0.2157 & -1.0787 & 0.9566 & 0.1069 & 0.2076 & 0.2102 & -1.0758 & 0.9588 \\
\hline $29 \mathrm{H}$ & 0.0899 & 0.3038 & 0.2248 & -1.0803 & 0.9522 & 0.0678 & 0.2724 & 0.2202 & -1.0782 & 0.9543 \\
\hline $30 \mathrm{H}$ & 0.1119 & 0.1600 & 0.2096 & -1.0983 & 0.9579 & 0.1268 & 0.1624 & 0.2106 & -1.0944 & 0.9575 \\
\hline $31 \mathrm{H}$ & 0.1375 & 0.1986 & 0.2235 & -1.1043 & 0.9530 & 0.1557 & 0.1845 & 0.2242 & -1.1011 & 0.9526 \\
\hline $32 \mathrm{H}$ & 0.1278 & 0.1747 & 0.2146 & -1.0985 & 0.9557 & 0.1424 & 0.1741 & 0.2161 & -1.0952 & 0.9550 \\
\hline $33 \mathrm{H}$ & 0.1312 & 0.1780 & 0.2130 & -1.0987 & 0.9564 & 0.1250 & 0.1785 & 0.2134 & -1.0965 & 0.9564 \\
\hline $34 \mathrm{H}$ & 0.1478 & 0.1460 & 0.2114 & -1.1006 & 0.9576 & 0.1536 & 0.1406 & 0.2105 & -1.0969 & 0.9579 \\
\hline $35 \mathrm{H}$ & 0.1314 & 0.1742 & 0.2169 & -1.0987 & 0.9548 & 0.1296 & 0.1897 & 0.2184 & -1.0964 & 0.9542 \\
\hline $36 \mathrm{H}$ & 0.1295 & 0.1373 & 0.2067 & -1.1026 & 0.9596 & 0.1042 & 0.1398 & 0.2079 & -1.1021 & 0.9591 \\
\hline $37 \mathrm{H}$ & 0.1288 & 0.1684 & 0.2097 & -1.1027 & 0.9579 & 0.1064 & 0.1679 & 0.2101 & -1.1022 & 0.9578 \\
\hline $38 \mathrm{H}$ & 0.1380 & 0.1770 & 0.2155 & -1.1020 & 0.9554 & 0.1132 & 0.1760 & 0.2156 & -1.1015 & 0.9554 \\
\hline $39 \mathrm{H}$ & 0.1761 & 0.1762 & 0.2156 & -1.1011 & 0.9552 & 0.1741 & 0.1760 & 0.2157 & -1.1005 & 0.9552 \\
\hline $40 \mathrm{H}$ & 0.1766 & 0.1705 & 0.2132 & -1.1010 & 0.9563 & 0.1766 & 0.1722 & 0.2134 & -1.1003 & 0.9562 \\
\hline $41 \mathrm{H}$ & 0.1950 & 0.1424 & 0.2098 & -1.1038 & 0.9590 & 0.1900 & 0.1250 & 0.2092 & -1.1028 & 0.9594 \\
\hline $42 \mathrm{H}$ & 0.4115 & 0.3001 & 0.3949 & -1.0018 & 0.8472 & 0.4054 & 0.3204 & 0.3983 & -0.9979 & 0.8443 \\
\hline $43 \mathrm{H}$ & 0.4185 & 0.3369 & 0.4137 & -1.0034 & 0.8331 & 0.4085 & 0.3394 & 0.4164 & -1.0003 & 0.8303 \\
\hline
\end{tabular}

Table S2. Main delocalization energies (in $\mathrm{kJ} / \mathrm{mol}$ ) of topiramate in gas phase and aqueous solution by using B3LYP/6-311++g(d,p) calculations.

\begin{tabular}{l|l|l}
\hline \multirow{2}{*}{ Delocalization } & \multicolumn{2}{c}{ B3LYP/6-311++g(d,p $)^{\mathbf{a}}$} \\
\cline { 2 - 3 } & \multicolumn{2}{|c}{ Topiramate } \\
\cline { 2 - 3 }$\sigma S 1-O 7 \rightarrow \sigma^{*} S 1-O 8$ & & Water \\
\hline$\sigma S 1-O 7 \rightarrow \sigma^{*} S 1-O 9$ & 11.78 & 11.28 \\
\hline$\sigma S 1-O 7 \rightarrow \sigma^{*} S 1-N 10$ & 11.91 & 12.20 \\
\hline$\sigma S 1-O 8 \rightarrow \sigma^{*} S 1-O 7$ & 18.43 & 17.55 \\
\hline$\sigma S 1-N 10 \rightarrow \sigma^{*} S 1-O 7$ & 14.96 & 13.62 \\
\hline$\sigma C 11-H 23 \rightarrow \sigma^{*} O 3-C 13$ & 17.51 & 16.21 \\
\hline$\sigma C 15-H 27 \rightarrow \sigma^{*} O 3-C 13$ & 13.79 & 13.20 \\
\hline$\sigma C 18-H 28 \rightarrow \sigma^{*} S 1-O 7$ & 14.92 & 13.21 \\
\hline$\sigma C 18-H 28 \rightarrow \sigma^{*} O 4-C 13$ & 19.31 & 19.52 \\
\hline$\sigma C 18-H 29 \rightarrow \sigma^{*} O 3-C 13$ & 19.01 & 20.39 \\
\hline$\sigma C 19-H 30 \rightarrow \sigma^{*} O 2-C 16$ & 20.39 & 21.69 \\
\hline$\sigma C 19-H 31 \rightarrow \sigma^{*} C 16-C 2$ & & 4.11 \\
\hline$\sigma C 19-H 32 \rightarrow \sigma^{*} O 4-C 16$ & 23.07 & 23.82 \\
\hline$\sigma C 20-H 33 \rightarrow \sigma^{*} O 4-C 16$ & 21.15 & 22.53 \\
\hline$\sigma C 20-H 34 \rightarrow \sigma^{*} C 16-C 19$ & 16.72 & 16.46 \\
\hline$\sigma C 20-H 35 \rightarrow \sigma^{*} O 2-C 16$ & 22.07 & 22.94 \\
\hline$\sigma C 21-H 36 \rightarrow \sigma^{*} C 17-C 22$ & 15.80 & 16.26
\end{tabular}




\begin{tabular}{|c|c|c|}
\hline \multirow{3}{*}{ Delocalization } & \multicolumn{2}{|c|}{ B3LYP/6-311++g(d,p $)^{\mathrm{a}}$} \\
\hline & \multicolumn{2}{|c|}{ Topiramate } \\
\hline & Gas & Water \\
\hline$\sigma C 31-H 37 \rightarrow \sigma^{*} O 6-C 17$ & 20.27 & 21.44 \\
\hline$\sigma C 21-H 38 \rightarrow \sigma^{*} O 5-C 17$ & 21.94 & 22.69 \\
\hline$\sigma C 22-H 39 \rightarrow \sigma^{*} O 5-C 17$ & 20.77 & 21.40 \\
\hline$\sigma C 22-H 40 \rightarrow \sigma^{*} O 6-C 17$ & 22.19 & 23.03 \\
\hline$\sigma C 22-H 41 \rightarrow \sigma^{*} C 17-C 21$ & 16.42 & 16.80 \\
\hline$\Delta E_{\sigma \rightarrow \sigma^{*}}$ & 362.41 & 370.35 \\
\hline$L P(1) O 2 \rightarrow \sigma^{*} O 4-C 16$ & 13.41 & 17.89 \\
\hline$L P(2) O 2 \rightarrow \sigma^{*} C 11-C 13$ & & 12.74 \\
\hline$L P(2) O 2 \rightarrow \sigma^{*} C 11-H 23$ & 33.27 & 30.09 \\
\hline$L P(2) O 2 \rightarrow \sigma^{*} C 16-C 19$ & 12.12 & \\
\hline$L P(2) O 2 \rightarrow \sigma^{*} C 16-C 2 O$ & 24.87 & 25.12 \\
\hline$L P(1) O 3 \rightarrow \sigma^{*} O 4-C 13$ & 17.13 & 16.30 \\
\hline$L P(2) O 3 \rightarrow \sigma^{*} C 11-C 13$ & 21.27 & 19.56 \\
\hline$L P(2) O 3 \rightarrow \sigma^{*} C 13-C 18$ & 33.02 & 32.26 \\
\hline$L P(2) O 3 \rightarrow \sigma^{*} C 14-C 15$ & 21.81 & 20.56 \\
\hline$L P(2) O 3 \rightarrow \sigma^{*} C 15-H 26$ & 23.28 & 22.48 \\
\hline$L P(1) O 4 \rightarrow \sigma^{*} O 2-C 16$ & 12.58 & 13.20 \\
\hline$L P(1) O 4 \rightarrow \sigma^{*} N 10-H 43$ & & 14.88 \\
\hline$L P(2) O 4 \rightarrow \sigma^{*} O 3-C 13$ & 56.47 & 56.30 \\
\hline$L P(2) O 4 \rightarrow \sigma^{*} C 16-C 19$ & 19.93 & 15.42 \\
\hline$L P(2) O 4 \rightarrow \sigma^{*} C 16-C 2 O$ & 12.33 & 17.43 \\
\hline$L P(2) O 5 \rightarrow \sigma^{*} O 6-C 17$ & & 14.96 \\
\hline$L P(2) O 5 \rightarrow \sigma^{*} C 12-C 14$ & 11.87 & 11.53 \\
\hline$L P(2) O 5 \rightarrow \sigma^{*} C 12-H 24$ & 31.68 & 30.51 \\
\hline$L P(2) O 5 \rightarrow \sigma^{*} C 17-C 21$ & 26.20 & 25.28 \\
\hline$L P(1) O 6 \rightarrow \sigma^{*} O 5-C 17$ & 15.80 & 14.33 \\
\hline$L P(2) O 6 \rightarrow \sigma^{*} C 14-C 15$ & 29.17 & 27.46 \\
\hline$L P(2) O 6 \rightarrow \sigma^{*} C 14-H 25$ & 12.45 & 11.91 \\
\hline$L P(2) O 6 \rightarrow \sigma^{*} C 17-C 21$ & 20.94 & 19.68 \\
\hline$L P(2) O 6 \rightarrow \sigma^{*} C 17-C 22$ & 18.68 & 18.05 \\
\hline$L P(1) O 7 \rightarrow \sigma^{*} S 1-08$ & & 12.24 \\
\hline$L P(2) O 7 \rightarrow \sigma^{*} S 1-N 10$ & 31.72 & 36.49 \\
\hline$L P(2) O 7 \rightarrow \sigma^{*} C 13-C 18$ & 28.50 & 23.53 \\
\hline$L P(2) O 8 \rightarrow \sigma^{*} S 1-O 7$ & 22.69 & 42.21 \\
\hline$L P(2) O 8 \rightarrow \sigma^{*} S 1-O 9$ & 30.05 & 16.42 \\
\hline$L P(2) O 8 \rightarrow \sigma^{*} S 1-N 10$ & 90.20 & 85.98 \\
\hline$L P(3) O 8 \rightarrow \sigma^{*} S 1-O 7$ & 113.11 & 86.14 \\
\hline$L P(3) O 8 \rightarrow \sigma^{*} S 1-O 9$ & 52.04 & 64.53 \\
\hline$L P(2) O 9 \rightarrow \sigma^{*} S 1-O 7$ & 19.72 & 23.53 \\
\hline$L P(2) O 9 \rightarrow \sigma^{*} S 1-O 8$ & 33.23 & 28.50 \\
\hline$L P(2) O 9 \rightarrow \sigma^{*} S 1-N 10$ & 92.75 & 88.69 \\
\hline$L P(3) O 9 \rightarrow \sigma^{*} S 1-O 7$ & 104.41 & 93.46 \\
\hline$L P(3) O 9 \rightarrow \sigma^{*} \mathrm{~S} 1-O 8$ & 54.38 & 56.84 \\
\hline$L P(1) N 10 \rightarrow \sigma^{*} S 1-O 7$ & 46.35 & 51.79 \\
\hline$\Delta E_{L P \rightarrow \sigma^{*}}$ & 1262.02 & 1269.15 \\
\hline 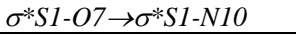 & 12.87 & 21.81 \\
\hline$\sigma^{*} S 1-07 \rightarrow \sigma^{*} 07-C 18$ & 18.81 & 27.50 \\
\hline$\Delta E_{\sigma^{*} \rightarrow \sigma^{*}}$ & 31.68 & 49.31 \\
\hline$\triangle E_{\text {TOTAL }}$ & 1656.11 & 1688.81 \\
\hline
\end{tabular}

Table S3. Analysis of the Bond Critical Points (BCPs) and Ring critical point (RCPs) for topiramate in gas phase by using the B3LYP/6-311++g(d,p) method.

\begin{tabular}{|c|c|c|c|c|c|c|c|c|c|}
\hline \multicolumn{10}{|c|}{ B3LYP/6-311++G(D,P) Method } \\
\hline \multicolumn{10}{|c|}{ GAS PHASE } \\
\hline Parameter $^{\#}$ & $\mathrm{H} 43-\mathrm{O} 4$ & $\mathrm{H} 28-\mathrm{O} 5$ & $\mathrm{H} 26-\mathrm{H} 41$ & RCPN1 & RCPN2 & RCPN3 & RCP1 & RCP2 & RCP3 \\
\hline$\rho(\mathrm{r})$ & 0.0202 & 0.0065 & 0.0051 & 0.0068 & 0.0061 & 0.0050 & 0.0194 & 0.0436 & 0.0440 \\
\hline$\nabla 2 \rho(\mathrm{r})$ & 0.0728 & 0.0212 & 0.0164 & 0.0328 & 0.0256 & 0.0192 & 0.1192 & 0.3004 & 0.2968 \\
\hline$\lambda 1$ & -0.0245 & -0.0051 & -0.0039 & -0.0026 & -0.0036 & -0.0029 & -0.0158 & -0.0472 & -0.0466 \\
\hline$\lambda 2$ & -0.0242 & -0.0039 & -0.0022 & 0.0150 & 0.0060 & 0.0029 & 0.0644 & 0.1613 & 0.1643 \\
\hline$\lambda 3$ & 0.1219 & 0.0307 & 0.0228 & 0.0206 & 0.0235 & 0.0192 & 0.0706 & 0.1865 & 0.1794 \\
\hline$|\lambda 1| / \lambda 3$ & 0.2009 & 0.1661 & 0.1710 & 0.1262 & 0.1531 & 0.1510 & 0.2237 & 0.2530 & 0.2597 \\
\hline Distances $(\AA)$ & 2.065 & 2.733 & 2.406 & & & & & & \\
\hline
\end{tabular}

"In a.u. 
Table S4. Analysis of the Bond Critical Points (BCPs) and Ring critical point (RCPs) for topiramate in aqueous solution by using the B3LYP/6-311++g(d,p) method.

\begin{tabular}{l|l|l|l|l|l|l|l}
\hline \multicolumn{7}{c}{ B3LYP/6-311++G(D,P) Method } \\
\hline Parameter $^{\#}$ & H43-O4 & H26-H41 & RCPN1 & RCPN2 & RCP1 & RCP2 & RCP3 \\
\hline$\rho(\mathrm{r})$ & 0.0203 & 0.0052 & 0.0075 & 0.0051 & 0.0191 & 0.0430 & 0.0431 \\
\hline$\nabla^{2} \rho(\mathrm{r})$ & 0.0744 & 0.0164 & 0.0340 & 0.0192 & 0.1172 & 0.2968 & 0.2924 \\
\hline$\lambda 1$ & -0.0244 & -0.0040 & -0.0034 & -0.0029 & -0.0156 & -0.0460 & -0.0455 \\
\hline$\lambda 2$ & -0.0237 & -0.0024 & 0.0097 & 0.0032 & 0.0633 & 0.1566 & 0.1588 \\
\hline$\lambda 3$ & 0.1230 & 0.0231 & 0.0281 & 0.0192 & 0.0698 & 0.1863 & 0.1793 \\
\hline$|\lambda 1| / \lambda 3$ & 0.1983 & 0.1731 & 0.1209 & 0.1510 & 0.2234 & 0.2469 & 0.2537 \\
\hline Distances $(\AA)$ & 2.067 & 2.397 & & & & & \\
\hline
\end{tabular}

${ }^{\#}$ In a.u

Table S5. Frontier molecular HOMO and LUMO orbitals, gap values and chemical potential $(\mu)$, electronegativity $(\chi)$, global hardness $(\eta)$, global softness $(S)$, global electrophilicity index $(\omega)$ and nucleophilicity indexes $(E)$ descriptors (in $e V$ ) of topiramate in gas phase and aqueous solution by using the B3LYP/6-311++G(D,P) level of theory.

\begin{tabular}{|c|c|c|c|c|c|c|}
\hline \multicolumn{3}{|c|}{ B3LYP/6-311++G** } & \multicolumn{4}{|c|}{ B3LYP/6-31G* } \\
\hline \multicolumn{3}{|c|}{ Topiramate $^{\mathrm{a}}$} & \multicolumn{2}{|c|}{ Scopolamine $^{\mathrm{b}}$} & \multicolumn{2}{|c|}{ Promethazine $^{c}$} \\
\hline Orbital & Gas & PCM & Gas & PCM & Gas & PCM \\
\hline HOMO & -7.5114 & -7.5024 & -5.7650 & -5.8338 & -5.0096 & -5.0559 \\
\hline LUMO & -0.5680 & -0.5708 & -0.3646 & -0.3580 & -0.2939 & -0.2857 \\
\hline $\mid$ GAP $\mid$ & 6.9434 & 6.9316 & 5.4004 & 5.4758 & 4.7157 & 4.7702 \\
\hline \multicolumn{7}{|c|}{ Descriptors } \\
\hline$\mu$ & -3.4717 & -3.4658 & -2.7002 & -2.7379 & -2.3579 & -2.3851 \\
\hline$\chi$ & -4.0397 & -4.0366 & -3.0648 & -3.0959 & -2.6518 & -2.6708 \\
\hline$\eta$ & 3.4717 & 3.4658 & 2.7002 & 2.7379 & 2.3579 & 2.3851 \\
\hline$S$ & 0.1440 & 0.1443 & 0.1852 & 0.1826 & 0.2121 & 0.2096 \\
\hline$\omega$ & 2.3503 & 2.3507 & 1.7393 & 1.7504 & 1.4911 & 1.4954 \\
\hline E & -14.025 & -13.990 & -8.2756 & -8.4763 & -6.2524 & -6.3701 \\
\hline
\end{tabular}

${ }^{\mathrm{a}}$ This work, ${ }^{\mathrm{b}}$ From Ref [35], ${ }^{\mathrm{c}} \mathrm{From}$ Ref [37]

$\chi=-[\mathrm{E}(\mathrm{LUMO})-\mathrm{E}(\mathrm{HOMO})] / 2 ; \mu=[\mathrm{E}(\mathrm{LUMO})+\mathrm{E}(\mathrm{HOMO})] / 2 ; \eta=[\mathrm{E}(\mathrm{LUMO})-\mathrm{E}(\mathrm{HOMO})] / 2 ; S=1 / 2 \eta ; \omega=\mu^{2} / 2 \eta ; \mathrm{E}=\mu * \eta$

Table S6. Observed and calculated ${ }^{1} \mathrm{H}$ chemical shifts $(\delta$ in ppm) for Topiramate in different media by using the B3LYP/6-311++G(D,P) method.

\begin{tabular}{l|l|l|l}
\hline \multicolumn{3}{|c|}{ Topiramate } & \multirow{2}{*}{$\operatorname{Exp}^{\mathrm{b}}$} \\
\hline $\mathrm{H}$ atom & Gas & Water & \\
\hline $23-\mathrm{H}$ & 3.90 & 3.94 & 4.33 \\
\hline $24-\mathrm{H}$ & 4.40 & 4.33 & 4.65 \\
\hline $25-\mathrm{H}$ & 4.17 & 4.14 & 4.28 \\
\hline $26-\mathrm{H}$ & 3.46 & 3.31 & 3.82 \\
\hline $27-\mathrm{H}$ & 3.74 & 3.71 & 3.94 \\
\hline $28-\mathrm{H}$ & 4.53 & 4.46 & 4.37 \\
\hline $29-\mathrm{H}$ & 4.33 & 4.16 & 4.27 \\
\hline $30-\mathrm{H}$ & 1.39 & 1.35 & 1.19 \\
\hline $31-\mathrm{H}$ & 1.64 & 1.49 & 1.19 \\
\hline $32-\mathrm{H}$ & 1.46 & 1.46 & 1.19 \\
\hline $33-\mathrm{H}$ & 1.28 & 1.14 & 1.19 \\
\hline $34-\mathrm{H}$ & 1.39 & 1.45 & 1.19 \\
\hline $35-\mathrm{H}$ & 1.53 & 1.41 & 1.19 \\
\hline $36-\mathrm{H}$ & 1.43 & 1.36 & 1.19 \\
\hline $37-\mathrm{H}$ & 1.14 & 1.07 & 1.19 \\
\hline $38-\mathrm{H}$ & 1.33 & 1.28 & 1.19 \\
\hline $39-\mathrm{H}$ & 1.53 & 1.47 & 1.19 \\
\hline $40-\mathrm{H}$ & 1.62 & 1.55 & 1.19 \\
\hline $41-\mathrm{H}$ & 1.25 & 1.17 & 1.19 \\
\hline $42-\mathrm{H}$ & 3.82 & 3.95 & 4.92
\end{tabular}




\begin{tabular}{l|l|l|l}
\hline \multicolumn{3}{|c|}{ Topiramate $^{\mathrm{a}}$} & \multirow{2}{*}{ Exp $^{\mathrm{b}}$} \\
\hline H atom & Gas & Water & \\
\hline $43-\mathrm{H}$ & 6.06 & 5.91 & 4.92 \\
\hline RMSD & $\mathbf{0 . 4 2}$ & $\mathbf{0 . 3 8}$ & \\
\hline
\end{tabular}

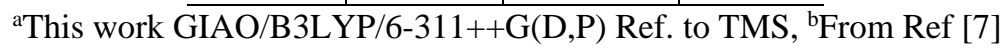

Table S7. Observed and calculated ${ }^{13} \mathrm{C}$ chemical shifts ( $\delta$ in ppm) for topiramate in different media by using the B3LYP/6-311++G(D,P) method.

\begin{tabular}{l|l|l|l}
\hline \multicolumn{3}{|c|}{ Topiramate $^{\mathrm{a}}$} & \multirow{2}{*}{ Exp $^{\mathrm{b}}$} \\
\hline C atoms & Gas & Water & \\
\hline $11-\mathrm{C}$ & 78.95 & 79.37 & 70.9 \\
\hline $12-\mathrm{C}$ & 77.80 & 77.63 & 70.9 \\
\hline $13-\mathrm{C}$ & 106.32 & 106.66 & 101.3 \\
\hline $14-\mathrm{C}$ & 72.27 & 72.57 & 70.0 \\
\hline $15-\mathrm{C}$ & 66.62 & 66.87 & 59.7 \\
\hline $16-\mathrm{C}$ & 119.34 & 119.84 & 120.1 \\
\hline $17-\mathrm{C}$ & 116.77 & 117.90 & 105.3 \\
\hline $18-\mathrm{C}$ & 68.50 & 71.35 & 70.0 \\
\hline 19-C & 28.32 & 27.00 & 28.1 \\
\hline 20-C & 26.67 & 24.54 & 27.2 \\
\hline 21-C & 25.58 & 25.13 & 25.9 \\
\hline 22-C & 29.14 & 28.78 & 26.8 \\
\hline RMSD & $\mathbf{4 . 6 9}$ & $\mathbf{5 . 0 1}$ & \\
\hline GIAO/B3LYP/6-311 &
\end{tabular}

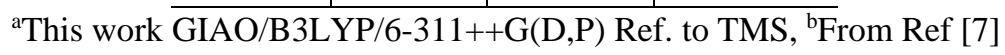

